This is the final peer-reviewed accepted manuscript of:

A.L. Razera, R.J.C. da Fonseca, L.A. Isoldi, E.D. dos Santos, L.A.O. Rocha, C. Biserni

"Constructal design of a semi-elliptical fin inserted in a lid-driven square cavity with mixed convection"

In: International Journal of Heat and Mass Transfer,Volume 126, Part B, 2018,P. 81-94

The final published version is available online at:

https://doi.org/10.1016/j.ijheatmasstransfer.2018.05.157

Rights / License:

The terms and conditions for the reuse of this version of the manuscript are specified in the publishing policy. For all terms of use and more information see the publisher's website.

This item was downloaded from IRIS Università di Bologna (https://cris.unibo.it/)

When citing, please refer to the published version. 


\title{
CONSTRUCTAL DESIGN OF A SEMI-ELLIPTICAL FIN INSERTED IN A LID-DRIVEN SQUARE CAVITY WITH MIXED CONVECTION
}

\author{
A. L. Razera ${ }^{1}$, R. J. C. da Fonseca ${ }^{1}$, L. A. Isoldi ${ }^{2}$, E. D. dos $\operatorname{Santos}^{2}$, L. A. O. Rocha ${ }^{3}$ and \\ C. Biserni ${ }^{4}$
}

\footnotetext{
${ }^{1}$ Department of Mechanical Engineering, Federal University of Rio Grande do Sul - UFRGS, Sarmento Leite Street, 425, Porto Alegre, RS, Brazil.

${ }^{2}$ Graduate Program of Ocean Engineering, School of Engineering, Federal University of Rio Grande - FURG, Rio Grande, Brazil, Italia Avenue, km 8, 96201-900.

${ }^{3}$ Mechanical Engineering Graduate Program, University of Vale do Rio dos Sinos - UNISINOS, São Leopoldo, RS, Brazil.

${ }^{4}$ Dipartimento di Ingegneria Industriale, Università degli Studi di Bologna, Viale Risorgimento 2, 40136 Bologna, Italy.
}

\begin{abstract}
The present study is focused on the geometric optimization, according to Constructal Design, of a semi-elliptical morphing fin, i.e. a fin that can vary its dimensions, inserted into a lid-driven square cavity under mixed convection. The fluid flow is considered incompressible, two-dimensional, laminar and at the steady state. Conservation equations of mass, momentum and energy are solved numerically by means of the Finite Volume Method. Moreover, buoyancy forces are modeled with Boussinesq approximation. The main purpose here is to maximize the dimensionless heat transfer rate between the heated fin and the surrounding flow for different Reynolds $\left(\operatorname{Re}_{H}=10,10^{2}\right.$ and $\left.10^{3}\right)$ and Rayleigh $\left(R a_{H}=10^{3}, 10^{4}, 10^{5}\right.$ and $\left.10^{6}\right)$ numbers keeping constant the Prandtl number $(\operatorname{Pr}=$ 0.71). The studied domain has two constraints (areas of fin and cavity) and one degree of freedom given by the aspect ratio between the height and length of the fin $\left(H_{1} / L_{1}\right)$, which is evaluated in three different surfaces of the cavity and four different area fractions of the fin. Results showed that the optimal configurations presented a gain in the thermal performance on the order of $40 \%$ in relation to other geometries. Finally, it is worth to mention that the optimal shapes here discovered are highly influenced by Reynolds and Rayleigh numbers.
\end{abstract}

Keywords: Constructal Design method, mixed convection, Nusselt and Rayleigh numbers, semielliptical fin, square cavity. 


\section{Nomenclature}

A area of the cavity $\left[\mathrm{m}^{2}\right]$

$\mathrm{A}_{\mathrm{f}} \quad$ area of the fin $\left[\mathrm{m}^{2}\right]$

$\mathrm{c}_{\mathrm{p}} \quad$ specific heat $\left[\mathrm{J} \mathrm{kg}^{-1} \mathrm{~K}^{-1}\right]$

$\mathrm{H} \quad$ cavity height [m]

$\mathrm{h}$ convective heat transfer coefficient $\left[\mathrm{W} \mathrm{m}^{-2} \mathrm{~K}^{-1}\right]$

$\mathrm{H}_{1} \quad$ ellipse vertical semi axis length [m]

$\mathrm{k}$ thermal conductivity [ $\mathrm{W} \mathrm{m}^{-1} \mathrm{~K}^{-1}$ ]

L cavity length [m]

$\mathrm{L}_{1} \quad$ ellipse horizontal semi axis length [m]

$\mathrm{Nu}_{\mathrm{H}} \quad$ Nusselt number based on cavity height

$\mathrm{P} \quad$ pressure $\left[\mathrm{N} \mathrm{m}^{-2}\right]$

Pr Prandtl number

$\mathrm{Ra}$ Rayleigh number based on cavity height

$\mathrm{Re}_{\mathrm{H}}$ Reynolds number based on cavity height

$\mathrm{T}$ temperature $[\mathrm{K}]$

$\mathrm{T}_{\infty} \quad$ bulk temperature $[\mathrm{K}]$

$\mathrm{u} \quad$ velocity in the $\mathrm{x}$-direction $\left[\mathrm{m} \mathrm{s}^{-1}\right]$

$\mathrm{u}_{\mathrm{us}} \quad$ velocity of the upper surface $\left[\mathrm{m} \mathrm{s}^{-1}\right.$ ]

$\mathrm{v} \quad$ velocity in the $\mathrm{y}$-direction $\left[\mathrm{m} \mathrm{s}^{-1}\right]$

$\mathrm{x}, \mathrm{y}$ spatial coordinates [m]

\section{Greek symbols}

$\alpha \quad$ thermal diffusivity $\left[\mathrm{m}^{2} \mathrm{~s}\right]$

$\beta \quad$ thermal expansion coefficient $\left[\mathrm{K}^{-1}\right]$

$v \quad$ kinematic viscosity $\left[\mathrm{m}^{2} \mathrm{~s}\right]$

$\rho \quad$ density $\left[\mathrm{kg} \mathrm{m}^{-3}\right]$

$\mu \quad$ dynamic viscosity $\left[\mathrm{kg} \mathrm{m}^{-1} \mathrm{~s}^{-1}\right]$

$\phi \quad$ area fraction

\section{Subscripts}

f fin variable 

$\max$ maximum
min minimum
o once optimized

\section{Superscripts}

( ) dimensionless variables

$\left(^{-}\right) \quad$ spatial-averaged variables

\section{INTRODUCTION}

The increasing requirement for miniaturization of structures in heat transfer removal, especially in electronic packages, makes the search for cooling solutions in these systems an important topic to be investigated. Convection heat transfer in cavity flows with inserted fins can ideally represent cooling in rooms, cars, solar panels and space between fins in heat exchangers. Therefore, several strategies have been employed to improve the thermal performance in these systems [1,2]. In this context, studies related to flow inside cavities have been carried out continuously over the years. Several works have been developed in order to obtain a better understanding of the fluid-dynamic behavior of isothermal flows inside cavities, under different flow regimes [3-8]. The lid-driven cavity flow is one of the most investigated problem in fluid dynamics framework; the "relative" computational simplicity is counterbalanced by complex physics phenomena such as the formation of main vortex, reattachment and detachment of boundary layers and possible secondary vortices.

Moallemi and Jang [9] studied numerically the effect of the Prandtl number on heat transfer by mixed convection in a square cavity with movement of superior surface, where it was observed that the effects of buoyancy were more evident for larger Prandtl numbers. Prasad and Koseff [10] evaluated, by means of the experimental investigation, the heat flux by mixed convection in a rectangular cavity with water. Their results indicated that the heat transfer rate is partially affected by the Richardson number variation. Sivasankaran et al. [11] observed the effects of the cavity slope on the heat convection behavior of the system. In addition to the above described studies, Refs. [12-19] treated mixed convective flows in similar domains. More specifically, the study of fins or obstacles in flows inside lid-driven cavities has been the subject of a precise literature. Chamkha et al. [20] analyzed the flow of the air through mixed convection inside a cavity with a square cylinder heated at its center by investigating the effect of the geometric variation of the cavity, as well as the Reynolds and Richardson numbers. Similarly, Oztop et al. [21] evaluated the 
effect of mixed convection in a cavity with a circular body in its interior. More recently, Gibanov et al. [22] investigated the heat transfer by mixed convection in a cavity with a conductive solid heated therein. Other important studies deserved attention [23-25]. In general, cavities and fins represent ideally several engineering problems so that the geometric optimization of morphing geometries has always been attractive for researchers. One possible option in order to evaluate the design in this kind of problem is to employ Constructal Design, which is a method based on the physical principle named Constructal Law. Firstly proposed by Bejan [26] in 1997, the Constructal Law of design and evolution postulates that, for any finite animated or inanimated flow system, to persist in time (to survive), its design must evolve in such way to easily the internal streams that flow through the thermodynamic system [27, 28]. In engineering, Constructal Design has been applied for geometric evaluation of several problems, as fundamental heat transfer, renewable energy and, even, solid mechanics ("flow of stresses") [29-36]. For the application of Constructal Design, it must be defined an objective function (i.e. a performance indicator), constraints (which can be physical and geometrical) and degrees of freedom that arise in the closure of equation system defined by constraints and geometrical variables. A detailed explanation and main steps related with the application of Constructal Design and Exhaustive Search (used in the present work) was presented in Ref.[37]. Recently, the Constructal Law has been applied for the solution of several research topics related to flow with heat transfer in cavities. Dos Santos et al. [38] employed the Constructal Design method to evaluate the effect of the geometry of a rectangular fin inserted into the bottom wall of a lid-driven square cavity, over heat exchange between the fin and the surrounding forced convective flow. The fin geometry was evaluated for different Reynolds numbers, considering a fixed Prandtl number $(\operatorname{Pr}=0.71)$. Similarly, Ref. [39] treated the same geometric configuration for different Reynolds and Rayleigh numbers, thus studying the effects of fin geometry on the heat transfer. Aldrighi et al. in Ref. [40] investigated the heat transfer by forced convection in a system composed of a cavity with a heated rectangular fin inserted in lower and lateral (upstream and downstream) surfaces, according to the Constructal Design method. Afterwards, Razera et al. in Ref. [41] evaluated the heat transfer by mixed convection for different conditions of flow, in a system that combines a square cavity and a triangular fin inserted in its bottom wall.

In this context, the present work is aimed at the geometric optimization of a morphing fin inserted into a lid-driven square cavity bathed by mixed convective flow. The effect of aspect ratio between the height and length of the fin $\left(H_{1} / L_{1}\right)$ over heat transfer rate between the heated fin and fresh surrounding flow has been numerically investigated. Moreover, the fin is mounted in three different placements of the cavity (lower, downstream and upstream surfaces). The influence of 
different Reynolds $\left(\operatorname{Re}_{H}=10,10^{2}\right.$ and $\left.10^{3}\right)$ and Rayleigh $\left(\mathrm{Ra}_{\mathrm{H}}=10^{3}, 10^{4}, 10^{5}\right.$ and $\left.10^{6}\right)$ numbers, as well as, different fraction of areas of the fin inserted in the cavity $(\phi=0.05,0.1,0.2$ and 0.3$)$ over the thermal performance and optimal shapes are also evaluated. It is worth mentioning that these problems have not been investigated yet in Refs. [39-41], even using "basic" rectangular and triangular fins. Here it is studied a semi-elliptical fin with variable aspect ratio. The extended surface is firstly considered in the lower plane of the cavity and then it is supposed to be located into the cavity sidewalls, i.e. upstream and downstream. The mixed convective flow is considered two-dimensional, laminar, incompressible and at the steady state. For estimation of buoyancy forces, the Boussinesq approximation is contemplated. In this sense, conservation equations of mass, momentum and energy are numerically solved with the Finite Volume Method, more precisely employing the software ANSYS FLUENT 14.0 [42, 43].

\section{MATHEMATICAL MODELING}

This paper proposes to evaluate, numerically, the thermal and fluid-dynamic behavior of a system that combines a lid-driven square cavity and a heated semi-elliptical fin. The main objective is to obtain the geometries that lead to the maximization of the heat transfer rate between the heated fin and the surrounding flow, which is at a lower temperature. As already mentioned, the extended surface is initially supposed to be located in the lower wall of the cavity and thereafter an evaluation of the fin inserted into the sidewalls of the cavity (upstream and downstream) will be performed. A schematic computational domain with boundary conditions and geometric variables of the studied problem is presented in Fig. 1. The mixed convection, laminar and incompressible flows at steadystate with constant thermophysical properties are modeled by continuity, momentum (in $x$ and $y$ directions) and energy conservation equations, which are given in coherence with Ref. [44]:

$$
\begin{aligned}
& \frac{\partial u}{\partial x}+\frac{\partial v}{\partial y}=0 \\
& \rho\left(u \frac{\partial u}{\partial x}+v \frac{\partial u}{\partial y}\right)+\frac{\partial P}{\partial x}-\mu\left(\frac{\partial^{2} u}{\partial x^{2}}+\frac{\partial^{2} u}{\partial y^{2}}\right)=0 \\
& \rho\left(u \frac{\partial v}{\partial x}+v \frac{\partial v}{\partial y}\right)+\frac{\partial P}{\partial y}-\mu\left(\frac{\partial^{2} v}{\partial x^{2}}+\frac{\partial^{2} v}{\partial y^{2}}\right)+\rho g \beta\left(T-T_{\infty}\right)=0
\end{aligned}
$$




$$
\rho C_{p}\left(u \frac{\partial T}{\partial x}+v \frac{\partial T}{\partial y}\right)-k\left(\frac{\partial^{2} T}{\partial x^{2}}+\frac{\partial^{2} T}{\partial y^{2}}\right)=0
$$

where $x$ and $y$ are the Cartesian coordinates in the horizontal and vertical directions, $u$ and $v$ are the velocities in horizontal and vertical directions of the flow, $P$ is the pressure; $T$ is the temperature and $T_{\infty}$ is the reference temperature. In order to generalize the results, parameters of the problem can be used in its dimensionless form, as given below:

$$
\begin{aligned}
& \left(\tilde{x}, \tilde{y}, \tilde{H}, \tilde{H}_{1}, \tilde{L}, \tilde{L}_{1}\right)=\frac{\left(x, y, H, H_{1}, L, L_{1}\right)}{A^{1 / 2}} \\
& \tilde{T}=\frac{T-T_{\min }}{T_{\max }-T_{\min }} \\
& (\tilde{u}, \tilde{v})=\frac{(u, v)}{u_{u s}}
\end{aligned}
$$

Concerning the boundary conditions of the problem, as can be noticed in Fig. 1, lateral and the bottom surfaces are considered adiabatic and with non-slip and impermeability conditions $(\tilde{u}=0$ and $\tilde{v}=0)$. The upper surface has prescribed dimensionless temperature, $\tilde{T}=0$, and it is driven with dimensionless velocities of $\tilde{u}_{u s}=1$ and $\tilde{v}=0$. For the fin, it is considered null velocity ( $\tilde{u}=0$ and $\tilde{v}=0$ ) and the hot spot dimensionless temperature, $\tilde{T}=1$. Thus, the flow is driven by the displacement of superior surface (forced convection) associated by fluid flow caused by temperature stratification in the domain by natural convection, i.e., a mixed convective flow. Moreover, the problem is supposed as two-dimensional, laminar, steady-state and incompressible, so that the thermophysical properties of the flow are kept constant throughout the domain, with exception of the density, which is taken into account with the use of the Boussinesq approximation. More precisely, its effect is considered as a body force in momentum equation [47]. The properties of the fluid and the flow employed in this work are given in Table 1. 


\begin{tabular}{cccc}
\hline \hline Property & Symbol & Magnitude & Unit \\
\hline Prandtl number & $P r$ & 0.710 & dimensionless \\
Thermal conductivity & $k$ & 0.025 & $\mathrm{~W} / \mathrm{m} . \mathrm{K}$ \\
Dynamic viscosity & $\mu$ & $1.775 \times 10^{-2}$ & $\mathrm{~kg} / \mathrm{m} . \mathrm{s}$ \\
Specific heat at constant pressure & $C_{p}$ & 1.000 & $\mathrm{~J} / \mathrm{kg} . \mathrm{K}$ \\
Density & $\rho$ & Boussinesq approximation & $\mathrm{kg} / \mathrm{m}^{3}$ \\
& & $0.0452\left(R a_{\mathrm{H}}=10^{3}\right)$ & \\
Thermal Expansion Coefficient & $\beta$ & $0.4523\left(R a_{\mathrm{H}}=10^{4}\right)$ & $1 / \mathrm{K}$ \\
& & $4.5234\left(R a_{\mathrm{H}}=10^{5}\right)$ & \\
Thermal diffusivity & $\alpha$ & $45.2345\left(R a_{\mathrm{H}}=10^{6}\right)$ & $\mathrm{m} / \mathrm{s}$ \\
\hline \hline
\end{tabular}

Table 1 - Properties of the fluid and the flow

In the geometric analysis, the Constructal Design method associated to the Exhaustive Search method [26-27, 45-46] has been adopted in order to determine the restrictions, the degrees of freedom and the objective in the evaluation of the system. The complete procedure of optimization with Constructal Design associated with Exhaustive Search was described in Ref. [37]. In order to explain its application in the present problem, Fig. 2 illustrates a flow chart with the mains steps of application of the methods for definition of flow system and definition of search space with Constructal Design and optimization step (Step 8). Figure 3 depicts the application of exhaustive search (Step 8) for evaluation of degree of freedom $\left(H_{1} / L_{1}\right)$, dimensionless parameters of the convective flow $\left(R e_{\mathrm{H}}\right.$ and $\left.R a_{\mathrm{H}}\right)$ and area fraction of the fin $(\phi)$. The geometry has two constraints: the first one is the total area of the cavity $(A)$, and the second one is the area occupied by the fin inside the cavity $\left(A_{f}\right)$, given, respectively, by:

$$
\begin{aligned}
& A=H \cdot L \\
& A_{f}=\frac{\pi \cdot H_{1} \cdot L_{1}}{4}
\end{aligned}
$$

in which $H$ and $L$ are, respectively, the height and the length of the square cavity, and $H_{1}$ and $L_{1}$ are the length of the elliptical semi-axis, respectively in the vertical and horizontal direction. 
A dimensionless relation between the area of the cavity $(A)$ and the area of the fin $\left(A_{f}\right)$ may be defined by the following equation:

$$
\phi=\frac{A_{f}}{A}
$$

In this way, it is possible to set the geometry of the system to any value of $\phi$, representing the fraction of the area occupied by the fin relative to the cavity. For the present study, the ratio between the height and the length of the cavity $(H / L)$ will be assumed as constant, its value being equal to unity, so as to form a square cavity $(H / L=1)$. The relation between the height and the length of the fin $\left(H_{1} / L_{1}\right)$ is the degree of freedom to be evaluated, which is varied to obtain the ratio $H_{1} / L_{1}$ that maximizes the heat transfer removal in the system for different conditions of the flow and for different values of the area fraction (precisely $\phi=0.05,0.10,0.20$ and 0.30 ). Thus, the evaluation of the system proceeds as illustrated in the steps of Fig. 3.

To evaluate the heat transfer in the system, it was used the Nusselt number, which is the dimensionless group that represents the ratio between the heat transfer by convection and by conduction [44], and indicates the magnitude of the heat transfer between the heated surface and the surrounding fluid. The Nusselt number is defined by [44]:

$$
N u_{\mathrm{H}}=\frac{h \cdot H}{k}=\frac{\partial \tilde{T}}{\partial \tilde{n}}
$$

where $H$ is the characteristic length of the flow based on the height of the cavity, and $\tilde{n}$ is the normal coordinate of the surface of the fin. For geometrical evaluation, it is used the spatial averaged Nusselt number from local $N u_{\mathrm{H}}$ obtained with Eq. (11) in several points of the semielliptical fin.

To characterize correctly the phenomenon of the boundary layer, another dimensionless group, the Reynolds number $\left(R e_{\mathrm{H}}\right)$ [44], is defined. In this study, $R e_{\mathrm{H}}$ has been calculated considering the height of the cavity as the characteristic length and evaluated for the following values: $10,10^{2}$ and $10^{3}$. Thus, the Reynolds number based on the characteristic length $H$ is given by [44]: 


$$
R e_{\mathrm{H}}=\frac{\rho \cdot u_{u s} \cdot H}{\mu}
$$

in which $u_{u s}$ is the velocity of the upper movable wall of the cavity.

Analyzing the phenomenon in the mixed convection viewpoint, the Rayleigh number was employed as a parameter to measure the contribution of natural convection for driven flow in the present work. In the present treatment, the Rayleigh number based on the height of the cavity is given by [44]:

$$
R a_{\mathrm{H}}=\frac{g \beta\left(T_{s}-T_{\infty}\right) H^{3}}{v \alpha}
$$

in which $g$ is the gravity acceleration in $y$ direction, $\beta$ is the thermal expansion coefficient, $T_{s}$ is the temperature on the fin surface, $T_{\infty}$ is the free stream temperature, and $v$ is the kinematic viscosity of the fluid. In this work, $g=-9.81 \mathrm{~m} / \mathrm{s}^{2}, v=0.01775 \mathrm{~m}^{2} / \mathrm{s}$, and $\beta=0.0452 \mathrm{~K}^{-1}, \beta=0.452 \mathrm{~K}^{-1}, \beta=$ $4.520 \mathrm{~K}^{-1}$, and $\beta=45.20 \mathrm{~K}^{-1}$, respectively for the set of values here adopted $R a_{\mathrm{H}}=10^{3}, R a_{\mathrm{H}}=10^{4}$, $R a_{\mathrm{H}}=10^{5}$ and $R a_{\mathrm{H}}=10^{6}$.

\section{NUMERICAL MODELING}

For the numerical analysis, a non-uniform two-dimensional mesh (in the directions $x$ and $y$ ) with triangular volumes has been considered. The numerical solution of the Eqs. (1)-(4) is obtained through the commercial software of dynamics of computational fluids ANSYS FLUENT 14.0, which is based on the Finite Volumes Method (FVM) [42, 43, 48].

For the case under study, it was used the model of laminar solution. The Boussinesq approximation was adopted to compute the buoyancy forces. For the treatment of the advective terms, the scheme of interpolation upwind of first order was applied to solve the momentum and the energy equations and the pressure discretization. With the use of the SIMPLEC (Semi-Implicit Method for Pressure-Linked Equations Consistent) algorithm, the coupling pressure-velocity was performed. The convergence of the calculations was considered reached when the residuals values for the conservation equations of mass, momentum and energy between two consecutive iterations were less than $10^{-6}, 10^{-6}$ and $10^{-8}$, respectively. The numerical model here employed has been validated in previous studies [39-41] and more details about the validity of the present numerical procedure can be seen in these works. 
The mesh adopted was chosen by means of successive refinements. The mesh was considered appropriate when the relative deviation of the spatial averaged Nusselt number $\left(\overline{N u_{\mathrm{H}}}\right)$ between meshes of different numbers of volumes were less than $0.5 \%$. Table 2 shows the results of the analysis of mesh quality for the system with $R e_{\mathrm{H}}=10^{2}, R a_{\mathrm{H}}=10^{4}, \phi=0.05$ and $\operatorname{Pr}=0.71$, in which the indexes $(j)$ and $(j+1)$ represent, respectively, the magnitude of $\overline{N u_{\mathrm{H}}}$ for the mesh evaluated and the mesh with the largest number of volumes.

After the realization of the tests, it was verified that the mesh with approximately 33,000 volumes may be considered adequate for the proposed study, presenting a deviation of $0.10 \%$ in relation to the mesh with the largest number of volumes and complying with the defined criterion.

\begin{tabular}{ccc}
\hline \hline & & $\mid \overline{N u_{\mathrm{H}}}(j)$ \\
Number of volumes & $\overline{N u_{\mathrm{H}}}(j+1) \mid$ & \\
& & $\overline{N u_{\mathrm{H}}}(j)$ \\
\hline 5,344 & 5.0075 & 0.6651 \\
21,292 & 4.9742 & 0.1960 \\
$\mathbf{3 3 , 2 4 8}$ & $\mathbf{4 . 9 6 4 5}$ & $\mathbf{0 . 1 0 1 3}$ \\
59,138 & 4.9595 & - \\
\hline \hline
\end{tabular}

Table 2 - Analysis of mesh quality for $R e_{\mathrm{H}}=10^{2}, R a_{\mathrm{H}}=10^{4}, \operatorname{Pr}=0.71, \phi=0.05$ and $H_{1} / L_{1}=0.5$

\section{RESULTS AND DISCUSSION}

Velocity and temperature fields were simulated in order to determine the aspect ratio $H_{1} / L_{1}$ that leads to the maximization of the average Nusselt number $\overline{N u_{\mathrm{H}}}$ calculated along the surface of the fin. Initially, it was investigated the fin mounted in the bottom wall of the cavity, and the results were obtained for different numbers of $R e_{\mathrm{H}}\left(10,10^{2}\right.$ and $\left.10^{3}\right)$ and $R a_{\mathrm{H}}\left(10^{3}, 10^{4}, 10^{5}\right.$ and $\left.10^{6}\right)$. The Prandtl number was kept constant for all simulations, with the value of $\operatorname{Pr}=0.71$, and, in a first moment, it was fixed the fraction of area in $\phi=0.05$. It is important to notice that the resolution adopted in the variation in the aspect ratio $H_{1} / L_{1}$ around the optimal points obtained was of $\Delta H_{1} / L_{1}$ $=0.05$.

Figure 4 shows the behavior of $\overline{N u_{\mathrm{H}}}$ in function of the variation of the degree of freedom $H_{1} / L_{1}$ for different conditions of flow, obtained for various magnitudes of $R a_{\mathrm{H}}$ and three different Reynolds numbers: $R e_{\mathrm{H}}=10,10^{2}$ and $10^{3}$, given by Figs. 4(a)-4(c), respectively. It is possible to observe that the curves presented in this figure demonstrate a similar trend, so that, by increasing 
the aspect ratio $H_{1} / L_{1}$, there has been an increase in the values of $\overline{N u_{\mathrm{H}}}$ up to a maximum point, and, from this maximum, the values of $\overline{N u_{\mathrm{H}}}$ tend to decrease with the increase of $H_{1} / L_{1}$. This behavior has already been observed in the literature by [39] and [41], in cavities with fins of rectangular and triangular geometries, respectively. Thus, an optimal intermediate condition was obtained for the aspect ratio $H_{1} / L_{1}$. The highest values of $\overline{N u_{\mathrm{H}}}$ were obtained with the highest $\operatorname{Re}_{\mathrm{H}}$ studied $\left(\operatorname{Re}_{\mathrm{H}}=\right.$ $10^{3}$ ), as expected. Moreover, it was observed that, as the values of $R a_{\mathrm{H}}$ increase, it occurs an increase in the values of $\overline{N u_{\mathrm{H}}}$.

In order to elucidate the behavior found in Fig. 3 for the effect of $H_{1} / L_{1}$ over $\overline{N u_{\mathrm{H}}}$, Fig. 5 illustrates the temperature fields and local Nusselt number for the extreme values of $H_{1} / L_{1}$ studied $\left(H_{1} / L_{1}=0.10\right.$ and $\left.H_{1} / L_{1}=2.50\right)$ are presented, as well as the optimal geometry point obtained, that corresponds to $\left(H_{1} / L_{1}\right)_{\mathrm{o}}=0.45$, for the condition in which $R e_{\mathrm{H}}=10^{2}, R a_{\mathrm{H}}=10^{5}$ and $\phi=0.05$. Evaluating the Figure 5(a), (in which $H_{1} / L_{1}=0.10$ ), it is possible to perceive the existence of smaller temperature gradients around the heated surface when compared to the optimal geometry, Fig. 5(b), given by $\left(H_{1} / L_{1}\right)_{\mathrm{o}}=0.45$. Besides, the local Nusselt number obtained in the geometry of $\left(H_{1} / L_{1}\right)_{\mathrm{o}}=$ 0.45 is slightly superior in practically every surface of the fin when compared to the geometry of $H_{1} / L_{1}=0.10$. By the Figure 5(c), $\left(H_{1} / L_{1}=2.50\right)$, a high temperature region is observed in the vicinity of the left side wall of the fin, which originates from a low velocity fluid recirculation, thus generating an unfavorable heat transfer zone in the system, due to the predominance of heat transfer by diffusion in this region. Along with this, it was perceived, through the curve of local Nusselt number of the Fig. 5(c), a low heat transfer in the left region of the fin, which contrasts with the high heat transfer in its opposite region (right wall of the fin), which receives the fluid current at low temperature. In spite of the achievement of highest magnitude for local Nusselt number for the case of Fig. 5(c), this magnitude is restricted to a low portion of surface, which not compensate the other regions with low magnitude for local Nusselt number. For the case depicted in Fig. $5\left(\operatorname{Re}_{\mathrm{H}}=\right.$ $10^{2}, R a_{\mathrm{H}}=10^{5}$ and $\left.\phi=0.05\right)$, a gain of approximately $25 \%$ was obtained in relation to the average Nusselt number $\left(\overline{N u_{\mathrm{H}}}\right)$ calculated on the surface of the fin, when comparing optimal geometry, $\left(H_{1} / L_{1}\right)_{0}=0.45$, with the lowest performance geometry $\left(H_{1} / L_{1}=0.10\right)$.

The best shapes reached in Fig. 5 are summarized in Fig. 6. More precisely, the behavior for $\left(H_{1} / L_{1}\right)_{\mathrm{o}}$ and $\left(\overline{N u_{\mathrm{H}}}\right)_{\text {Max }}$ in function of different Reynolds numbers $\left(R e_{\mathrm{H}}\right)$ and for different Rayleigh numbers $\left(R a_{\mathrm{H}}\right)$ are presented in Figs. 6(a) and 6(b), respectively. Figure 6(a) shows that, with the increase of $R e_{\mathrm{H}}$, the optimal geometries obtained a decreasing behavior for $R a_{\mathrm{H}}=10^{3}\left(R e_{\mathrm{H}}=10\right.$, 
$\left(H_{1} / L_{1}\right)_{\mathrm{o}}=0.55 ; R e_{\mathrm{H}}=10^{2},\left(H_{1} / L_{1}\right)_{\mathrm{o}}=0.50 ;$ and $\left.R e_{\mathrm{H}}=10^{3},\left(H_{1} / L_{1}\right)_{\mathrm{o}}=0.40\right)$ and $R a_{\mathrm{H}}=10^{4}\left(R e_{\mathrm{H}}=\right.$ $10^{3},\left(H_{1} / L_{1}\right)_{\mathrm{o}}=0.45 ; R e_{\mathrm{H}}=10^{2},\left(H_{1} / L_{1}\right)_{\mathrm{o}}=0.45$; and $\left.R e_{\mathrm{H}}=10^{3},\left(H_{1} / L_{1}\right)_{\mathrm{o}}=0.40\right)$. For $R a_{\mathrm{H}}=10^{5}$, all the optimal geometry points obtained were the same for the different values of $R e_{\mathrm{H}}$ studied, given by $\left(H_{1} / L_{1}\right)_{\mathrm{o}}=0.45$. For the case in which $R a_{\mathrm{H}}=10^{6}$, the curve shows increasing as the Reynolds number increases $\left(R e_{\mathrm{H}}=10,\left(H_{1} / L_{1}\right)_{\mathrm{o}}=0.40 ; R e_{\mathrm{H}}=10^{2},\left(H_{1} / L_{1}\right)_{\mathrm{o}}=0.50 ;\right.$ and $R e_{\mathrm{H}}=10^{3},\left(H_{1} / L_{1}\right)_{\mathrm{o}}=$ 0.50). Figure 6(b) presents the influence of the number of $R e_{\mathrm{H}}$ on behavior of $\left(\overline{N u_{\mathrm{H}}}\right)_{\mathrm{Max}}$ for different values of $R a_{\mathrm{H}}$ studied. It is important to notice that, as $R e_{\mathrm{H}}$ increases, the values obtained for $\left(\overline{N u_{\mathrm{H}}}\right)_{\text {Max }}$ continuously increase to all values of $R a_{\mathrm{H}}$ evaluated. It is worth noting that, as the value of $R a_{\mathrm{H}}$ increases, the curves begin to present a smaller slope, tending to a constant, which show that, for elevated values of $R a_{\mathrm{H}}$, the average Nusselt number obtained for the optimal geometries become less sensitive to the variation of the Reynolds number. This behavior can be visualized through Fig. 7, which shows the temperature fields of the optimal geometries $\left(\left(H_{1} / L_{1}\right)_{\mathrm{o}}\right)$ obtained for $R a_{\mathrm{H}}=10^{4}, \phi=0.05$ and $P r=0.71$, in which: (a) $R e_{\mathrm{H}}=10$; (b) $R e_{\mathrm{H}}=10^{2}$; and (c) $R e_{\mathrm{H}}=$ $10^{3}$. In this way, it is evidenced that, with the increase of $R e_{\mathrm{H}}$, there is an increase in the temperature gradients around the surface where it is desired to remove heat, a phenomenon that is generated by the greater interaction of the heated surface of the fin with the fluid at a higher flux rate and that favors the heat transfer mechanism by forced convection on the system. Concerning the optimal shapes, it is also worthy to mention that the effect of Reynolds number over $\left(H_{1} / L_{1}\right)_{\mathrm{o}}$ changed with variation on the magnitude of $R a_{\mathrm{H}}$, indicating that the magnitude of flow system has a strong influence in its design.

Comparing the results of the present work with studies published in the literature, Fig. 8 shows the effect of the aspect ratio $H_{1} / L_{1}$ on the average Nusselt number $\left(\overline{N u_{\mathrm{H}}}\right)$ in cavities with fins of different geometries: elliptical (present work), rectangular [39] and triangular [41], for $R a_{\mathrm{H}}=$ $10^{5}, \phi=0.05$ and $\operatorname{Pr}=0.71$, in which: (a) $R e_{\mathrm{H}}=10$; (b) $R e_{\mathrm{H}}=10^{2}$; and (c) $R e_{\mathrm{H}}=10^{3}$. By Figure $8(\mathrm{a})$, in which the condition of $R e_{\mathrm{H}}=10$ was analyzed, it is observed that the maximum heat transfer, obtained for the fins of different geometries, reached very close values in magnitude, so that the cavity with the semi-elliptical geometry fin presented a better performance in terms of the heat transfer, with a gain of approximately $1 \%$ in relation to the cavity with triangular geometry fin and $10 \%$ in relation to the cavity with the rectangular fin. For $\operatorname{Re}_{\mathrm{H}}=10^{2}$, Figure $8(\mathrm{~b})$, the cavity with the semi-elliptical geometry fin presented an even greater thermal performance in relation to the flow with $R e_{\mathrm{H}}=10$, presenting a gain of heat transfer of approximately $16 \%$ and $15 \%$, respectively, over the fins of triangular and rectangular geometries. Similarly, for $R e_{\mathrm{H}}=10^{3}$, Fig. 
8(c), the semi-elliptical fin presented a superior thermal performance in relation to the other geometries, with approximate gains of $12 \%$ and $23 \%$, respectively, over the fins of triangular and rectangular geometries. In addition, it can be seen from Fig. 7 that the optimal aspect ratio $\left(H_{1} / L_{1}\right)$ is different for the analyzed cases, which shows that the geometry of the system adapted for the different flow conditions, so that the flow rate is facilitated, and thus, the goal of maximizing heat transfer is achieved.

In a second moment, the thermal behavior of the fin inserted in the side walls of the cavity is studied, evaluating the effects of heat transfer in the system for different values of the aspect ratio $H_{1} / L_{1}$ and for different flow conditions. Figure 9 shows a comparison of the effect of the aspect ratio $H_{1} / L_{1}$ on the average Nusselt number $\left(\overline{N u_{\mathrm{H}}}\right)$ calculated on the surface of the fin, considering the semi-elliptical fin inserted into the lower, right and left walls of the cavity for $\operatorname{Re}_{\mathrm{H}}=10^{2}$ and $P r$ =0.71, where: (a) $R a_{\mathrm{H}}=10^{3}$; (b) $R a_{\mathrm{H}}=10^{4}$; (c) $R a_{\mathrm{H}}=10^{5}$; and (d) $R a_{\mathrm{H}}=10^{6}$. By Figure 9(a), it is observed that the fin inserted in the wall of the cavity presented a better performance in the heat transfer in relation to the fin inserted in the other positions studied, in which the optimal case $\left(\left(H_{1} / L_{1}\right)_{\mathrm{o}}=0.40\right.$ and $\left.\left(\overline{N u_{\mathrm{H}}}\right)_{\mathrm{Max}}=5.0337\right)$ presented a gain of approximately $23 \%$ in relation to the fin inserted in the inferior wall of the cavity $\left(\left(H_{1} / L_{1}\right)_{\mathrm{o}}=0.50\right.$ and $\left.\left(\overline{N u_{\mathrm{H}}}\right)_{\mathrm{Max}}=3.8586\right)$ and $4.40 \%$ in relation to the fin inserted in the left wall of the cavity $\left(\left(H_{1} / L_{1}\right)_{\mathrm{o}}=0.40\right.$ and $\left.\left(\overline{N u_{\mathrm{H}}}\right)_{\mathrm{Max}}=4.8135\right)$. As the Rayleigh number increases, the fin inserted in the left wall of the cavity proved to be more adequate in relation to the other geometries, since, when the optimal cases obtained for the different positions of the fin in the cavity were compared, the fin inserted in the left wall presented approximate gains in heat transfer of up to $20 \%$ for $R a_{\mathrm{H}}=10^{4}, 38 \%$ for $R a_{\mathrm{H}}=10^{5}$ and $17 \%$ for $R a_{\mathrm{H}}$ $=10^{6}$.

This behavior can be explained by Fig. 10, which shows the temperature fields obtained for the fin inserted in the lower, left and right wall of the cavity for $\operatorname{Re}_{\mathrm{H}}=10^{2}, \operatorname{Pr}=0.71, \phi=0.05$ and $H_{1} / L_{1}=0.50$, in which: (a) $R a_{\mathrm{H}}=10^{3}$; (b) $R a_{\mathrm{H}}=10^{4}$; (c) $R a_{\mathrm{H}}=10^{5}$; and (d) $R a_{\mathrm{H}}=10^{6}$. Thus, for $R a_{\mathrm{H}}=10^{3}$ (Fig. 9 (a) and Fig. 10 (a)), the fin inserted in the right wall of the cavity is favored, relative to the fin positioned on the other walls of the cavity, since the main stream of the flow tangents its surface, increasing the temperature gradients in its surroundings, which favors the heat transfer between the flow and the heated surface. As $R a_{\mathrm{H}}$ increases (Figs. 9(b), 9(c) and 9(d), and Figs. 10(b), 10(c) and 10(d)), the fin inserted into the right (downstream) surface of the cavity presents an unfavorable condition for the system, as a result of the increase in the Rayleigh number, the effects of the natural convection of the system act in opposite direction to the main stream of the 
forced convective flow (which is given by imposition of fluid flow on the upper surface of the cavity). Thus, the heat transfer is disadvantageous in relation to the fin inserted in the other walls of the cavity, and this phenomenon becomes more visible through Figs. 10(c) and 10(d). On the other hand, the increase in the Rayleigh number favors the system when the fin is installed in the left wall of the cavity, so that the buoyancy effects generated by the temperature differences of the system act in the same direction as the forced stream of the flow, increasing the temperature gradients surrounding the surface of the fin and, thus, facilitating the removal of heat from the heated surface, which may be visualized through Fig. 10(d).

Among the evaluated cases, the highest values of average Nusselt number $\left(\left(\overline{N u_{\mathrm{H}}}\right)_{\mathrm{Max}}\right)$ were obtained for $R a_{\mathrm{H}}=10^{6}$. The temperature fields for the optimal geometries found, considering the fin installed in the walls inferior, left and right of the cavity are presented in Fig. 11, for $R a_{\mathrm{H}}=10^{6}, R e_{\mathrm{H}}$ $=10^{2}, \phi=0.05$ and $\operatorname{Pr}=0.71$. Comparing the temperature fields presented in Fig. 11, it is possible to observe that, for the fin inserted in the left wall of the cavity (represented in Fig. 11(a)), there is the condition of higher temperature gradients in the system; in other words, the fluid surrounding the heated surface is at a lower temperature relative to the cases in which the fin is positioned on the bottom wall (represented in Fig. 11 (b)) and the right wall (represented in Fig. 11 (c)) of the cavity, thereby justifying its better heat transfer performance.

Lastly, it was investigated the effect of the variation of the aspect ratio $H_{1} / L_{1}$ on the average Nusselt number $\left(\overline{N u_{\mathrm{H}}}\right)$ for different values of the fraction of area $\phi(0.05,0.10,0.20$ and 0.30$)$. For this analysis, the Reynolds and Rayleigh numbers were kept constant. So, Figure 12 illustrates the behavior for the condition in which $R e_{\mathrm{H}}=10^{3}, R a_{\mathrm{H}}=10^{5}$ and $\operatorname{Pr}=0.71$, where: (a) fin is mounted on the bottom wall of the cavity; (b) fin is mounted on the left wall of the cavity; and (c) fin is mounted on the right wall of the cavity. Figure 12(a) shows the behavior obtained for the fin inserted in the bottom wall of the cavity where it can be observed that, with the increase of the ratio $H_{1} / L_{1}$, there is a growth of the values of $\overline{N u_{\mathrm{H}}}$ up to a maximum point, so that, from this maximum, the values of the average Nusselt number tend to decrease with the increase of the aspect ratio. An exception for this behavior is obtained with the configuration $\phi=0.30$, where the maximum value of $\overline{N u_{\mathrm{H}}}$ is obtained for the lowest value of $H_{1} / L_{1}$, i.e., the minimum physically possible value for this situation. Results obtained were similar to those found by [41], which studied the behavior of $\phi$ for a triangular fin inserted in the lower wall of a square cavity, for the same conditions of flow. So, for $\phi=0.05$, the maximum Nusselt number obtained was $\left(\overline{N u_{\mathrm{H}}}\right)_{\mathrm{Max}}=12.3163$, found for the optimal aspect ratio given by $\left(H_{1} / L_{1}\right)_{0}=0.45$. For $\phi=0.10$, the maximum Nusselt Number obtained 
was of $\left(\overline{N u_{\mathrm{H}}}\right)_{\mathrm{Max}}=9.9511$, also found for the optimal aspect ratio given by $\left(H_{1} / L_{1}\right)_{\mathrm{o}}=0.45$. For $\phi=$ 0.20, $\left(\overline{N u_{\mathrm{H}}}\right)_{\mathrm{Max}}=7.5660$, obtained with $\left(H_{1} / L_{1}\right)_{\mathrm{o}}=0.40$. Finally, for $\phi=0.30$, the maximum Nusselt Number obtained was $\left(\overline{N u_{\mathrm{H}}}\right)_{\text {Max }}=6.2983$, also found for the optimal aspect ratio given by $\left(H_{1} / L_{1}\right)_{\mathrm{o}}=0.40$.

Concerning the lateral walls, Figs. 12(b) and 12(c) show, respectively, the thermal behavior of the system for the fin inserted in the left and right walls of the cavity. By these figures, it is possible to note that the behavior of the curves presented for the fin at different positions inside the cavity are very similar to each other, mainly for values of $\phi=0.10, \phi=0.20$ and $\phi=0.30$ where the curves present a decreasing behavior for $\overline{N u_{\mathrm{H}}}$ with the increase of $H_{1} / L_{1}$. For $\phi=0.05$, the behavior is dissimilar for the lowest magnitudes of $H_{1} / L_{1}\left(H_{1} / L_{1} \leq 0.20\right)$ where for the fin in the right surface is noticed a decrease of Nusselt number followed by an increase until the achievement of the highest magnitude of $\overline{N u_{\mathrm{H}}}$. For the fin installed in the left wall of the cavity, the curve showed an increasing behavior to a maximum point as $H_{1} / L_{1}$ increased, followed by a decrease in Nusselt values from this point. Thus, for $\phi=0.05$, the optimal aspect ratio and the maximum Nusselt number are given, respectively, by $\left(H_{1} / L_{1}\right)_{\mathrm{o}}=0.30$ and $\left(\overline{N u_{\mathrm{H}}}\right)_{\text {Max }}=14.0704$, for the fin inserted into the left wall of the cavity, and $\left(H_{1} / L_{1}\right)_{\mathrm{o}}=0.10$ and $\left(\overline{N u_{\mathrm{H}}}\right)_{\mathrm{Max}}=13.9688$, for the fin inserted in the right wall of the cavity. For $\phi=0.10$, the optimal aspect ratio and the maximum Nusselt number are given, respectively, by $\left(H_{1} / L_{1}\right)_{\mathrm{o}}=0.25$ and $\left(\overline{N u_{\mathrm{H}}}\right)_{\text {Max }}=11.2344$, for the fin inserted in the left wall of the cavity, and $\left(H_{1} / L_{1}\right)_{\mathrm{o}}=0.15$ and $\left(\overline{N u_{\mathrm{H}}}\right)_{\mathrm{Max}}=12.8538$, for the fin inserted in the right wall of the cavity. For $\phi=0.20$, the optimal aspect ratio for both cases was of $\left(H_{1} / L_{1}\right)_{\mathrm{o}}=0.30$, obtained for a maximum Nusselt number of $\left(\overline{N u_{\mathrm{H}}}\right)_{\operatorname{Max}}=10.0351$ and $\left(\overline{N u_{\mathrm{H}}}\right)_{\operatorname{Max}}=$ 11.4158, respectively, for the fin inserted in the left and right wall of the cavity. Finally, for $\phi=$ 0.30, the optimal aspect ratio for both cases was of $\left(H_{1} / L_{1}\right)_{\mathrm{o}}=0.40$, obtained for a maximum Nusselt number of $\left(\overline{N u_{\mathrm{H}}}\right)_{\mathrm{Max}}=13.1964$ and $\left(\overline{N u_{\mathrm{H}}}\right)_{\mathrm{Max}}=14.0110$, respectively, for the fin inserted in the left and right wall of the cavity.

In general, results of Fig. 12 showed that the lowest fraction of area $(\phi=0.05)$ conducted to the best thermal performance once this configuration is the one that gives more freedom to fluid flow inside the cavity domain. Results indicate that the combination between high heat exchange area for the fin and freedom for fluid flow conducts to the best thermal performance in this kind of problem. 
Figure 13 shows the effect of the fraction of area $(\phi)$ on the behavior of optimal geometries $\left(H_{1} / L_{1}\right)_{\mathrm{o}}$, given by Fig. 13(a), and the maximum Nusselt number $\left(\overline{N u_{\mathrm{H}}}\right)_{\text {Max }}$, given by Fig. 13(b), for $R e_{\mathrm{H}}=10^{3}, R a_{\mathrm{H}}=10^{5}$ and $\operatorname{Pr}=0.71$. Thus, as the fraction of area ( $\phi$ ) increases, Fig. 13(a), the optimal geometries $\left(\left(H_{1} / L_{1}\right)_{\mathrm{o}}\right)$ obtained for the system increase for the three fin configurations studied. When analyzing the effect of $\phi$ in relation to the maximum Nusselt number $\left(\overline{N u_{\mathrm{H}}}\right)_{\mathrm{Max}}$ for the fin inserted in the lower wall of the cavity, Fig. 13(b), it was verified that, with the increase of $\phi$, the values of $\left(\overline{N u_{\mathrm{H}}}\right)_{\text {Max }}$ decrease. In this case, the increase of fin area in relation to the cavity area is detrimental to the heat transfer in the system due to a strong restriction of fluid movement in the left region of the cavity, which also leads to low thermal gradients and heating of fluid flow in this region. The behavior obtained for the fin inserted in the side walls of the cavity follows the same principle previously analyzed within the range $0.05 \leq \phi \leq 0.20$, so that the maximum values of Nusselt number were decreasing with the increase of $\phi$. On the other hand, for $\phi=0.30$, there was an increase in the value of $\left(\overline{N u_{\mathrm{H}}}\right)_{\mathrm{Max}}$; thus, for this condition of $\phi$ (considering the fin inserted in the lateral walls of the system), the increase of the area of the fin in relation to the area of the cavity was favorable to the flow due to the proximity between the heated fin and the upper wall, which is at the lowest temperature magnitude. This proximity conducts to a strong increase of temperature gradient in the upper region of the fin.

\section{CONCLUSIONS}

This work evaluated numerically, through the Constructal Design method associated to the Exhaustive Search optimization method, the influence of the design over the thermal performance of a system composed of a mixed convective flow in lid-driven cavity with inserted heated semielliptical fin. More precisely, it was evaluated the effect of the ratio $H_{1} / L_{1}$ over the thermal performance for different Reynolds $\left(10 \leq R e_{\mathrm{H}} \leq 10^{3}\right)$ and Rayleigh $\left(10^{3} \leq R a_{\mathrm{H}} \leq 10^{6}\right)$ numbers, different fractions of area $(0.05 \leq \phi \leq 0.2)$. Moreover, three different placements where the fin is mounted were investigated: lower, upstream and downstream surfaces of the cavity. The main purpose here was to maximize the spatial averaged Nusselt number $\left(\overline{N u_{\mathrm{H}}}\right)$, calculated on the surface of the fin. For all cases, the Prandtl number was constant $(P r=0.71)$. For each case, conservation equations of mass, momentum and energy were solved with the Finite Volume Method. Several conclusions and ideas for future research emerged from this study.

Initially, the semi-elliptical fin inserted in the inferior wall of the cavity was evaluated, where the influence of the aspect ratio $H_{1} / L_{1}$ was verified for different flow conditions, keeping 
constant the value for $\phi(\phi=0.05)$. In this way, optimal geometric recommendations $\left(H_{1} / L_{1}\right)_{\mathrm{o}}$ were obtained that maximized the Nusselt number $\left(\left(\overline{N u_{\mathrm{H}}}\right)_{\mathrm{Max}}\right)$ for the different system conditions. A comparison with previous fin shapes (rectangular and triangular) inserted in lid-driven square cavity flow obtained in literature, Refs. [39, 41], for the same thermal conditions was performed. Results indicated that the employment of semi-elliptical fin led to a better thermal performance, providing gains of up to $23 \%$ in relation to the other geometries.

In a second moment, the thermal behavior of the fin inserted in the lateral walls of the cavity was studied, also evaluating the effects of the heat transfer in the system for different values of the aspect ratio $H_{1} / L_{1}$, still for $\phi=0.05$. Under the flow conditions studied, it was verified that the fin, when installed on the sidewalls of the cavity, provided a better thermal performance of the system, since, for $R e_{\mathrm{H}}=10^{2}$ and $R a_{\mathrm{H}}=10^{3}$, the fin coupled to the right wall obtained the highest values for $\overline{N u_{\mathrm{H}}}$. On the other hand, for this case, the fin installed in the lower wall showed the lowest performance. For $R e_{\mathrm{H}}=10^{2}$, and $R a_{\mathrm{H}}=10^{4}, R a_{\mathrm{H}}=10^{5}$ and $R a_{\mathrm{H}}=10^{6}$, the fin coupled to the left wall presented better heat transfer results. In these cases, the fin installed in the lower wall of the cavity presented intermediate results among the three configurations studied.

To summarize, the area fraction (between the fin and the cavity, $\phi$ ) was also analyzed, so that optimal geometric recommendations were outlined by means of the variation of $H_{1} / L_{1}$, for different values of $\phi$. By the variation of this parameter, it was observed that the heat transfer between the fin and the surrounding fluid was strongly affected and presented distinct characteristics among the evaluated cases, showing that the position of the fin in the system should be evaluated for each specific condition of the problem. In general, results indicated the importance to give freedom for fluid flow inside the cavity domain, since the performance with $\phi=$ 0.05 was the best in almost all the studied cases.

Finally, through the results obtained, it was possible to verify that different system conditions (flow, fin position in the cavity and fraction of area) require different geometric configurations of $H_{1} / L_{1}$, so that the best heat transfer performance is achieved. This is fully consistent to the Constructal principle that "freedom is good for design", i.e. freedom to change the configuration of the system by varying its degrees of freedom will make possible to discover the design which performs the best.

\section{Acknowledgements.}


The authors A.L. Razera, R.J. da Fonseca, E.D. dos Santos, L.A. Isoldi and L.A.O. Rocha, acknowledge CNPq (National Counsel of Technological and Scientific Development - Brasília, DF, Brazil), CAPES (Coordination for the Improvement of Higher Education Personnel) and Unisinos Office of Research and Graduate Studies (UAPPG) for the financial support. The author Cesare Biserni was sponsored by the Italian Ministry for Education, University and Research.

\section{REFERENCES}

[1] E. Fontana, C. A. Capeletto, A. da Silva, and V. C. Mariani, Numerical analysis of mixed convection in partially open cavities heated from below, Int. J. Heat Mass Transfer 81 (2015) 829845 .

[2] S. Durgam, S. P. Venkateshan, and T. Sundararajan, Experimental and numerical investigations on optimal distribution of heat source array under natural and forced convection in a horizontal channel, Int. J. Therm. Sci. 115 (2017) 125-138.

[3] J. R. Koseff, and R. L. Street, The lid-driven cavity flow: a synthesis of qualitative and quantitative observations, J. Fluids Eng. 106 (4) (1984) 390-398.

[4] A. K. Prasad, and J. R. Koseff, Reynolds number and end-wall effects on a lid-driven cavity flow, Phys. Fluids A: Fluid Dynamics 1 (2) 1989 208-218.

[5] T. P. Chiang, W. H. Sheu, and R. R. Hwang, Effect of Reynolds number on the eddy structure in a lid-driven cavity, Int. J. Numer. Meth. Fluids 26 (5) (1998) 557-579.

[6] P. N. Shankar, and M. D. Deshpande, Fluid mechanics in the driven cavity, Annual Rev. Fluid Mech. 32 (1) (2000) 93-136.

[7] E. Erturk, and C. Gökçöl, Fourth-order compact formulation of Navier-Stokes equations and driven cavity flow at high Reynolds numbers, Int. J. Numer. Meth. Fluids 50 (4) (2006) 421-436.

[8] L. S. Lin, Y. C. Chen, and C. A. Lin, Multi relaxation time lattice Boltzmann simulations of deep lid driven cavity flows at different aspect ratios, Comput. Fluids 45 (1) (2011) 233-240.

[9] M. K. Moallemi, and K. S. Jang, Prandtl number effects on laminar mixed convection heat transfer in a lid-driven cavity, Int. J. Heat Mass Transf. 35 (8) (1992) 1881-1892.

[10] A. K. Prasad, and J. R. Koseff, 1996, Combined forced and natural convection heat transfer in a deep lid-driven cavity flow, Int. J. Heat Fluid Flow 17 (5) (1992) 460-467. 
[11] S. Sivasankaran, V. Sivakumar, and A. K. Hussein, Numerical study on mixed convection in an inclined lid-driven cavity with discrete heating, Int. Commun. Heat Mass Transf. 46 (2013) 112125.

[12] M. Morzynski, and C. O. Popiel, Laminar heat transfer in a two-dimensional cavity covered by a moving wall, Numer. Heat Transf. 13 (2) (1988) 265-273.

[13] A. Mohamad, and R. Viskanta, Flow and thermal structures in a lid-driven cavity heated from below, Fluid Dyn. Res. 12 (3) (1993) 173-184.

[14] R. Iwatsu, J. M. Hyun, and K. Kuwahara, Mixed convection in a driven cavity with a stable vertical temperature gradient, Int. J. Heat Mass Transf. 36 (6) (1993) 1601-1608.

[15] R. Iwatsu, and J. M. Hyun, Three-dimensional driven-cavity flows with a vertical temperature gradient, Int. J. Heat Mass Transf. 38 (18) (1995) 3319-3328.

[16] E. D. Dos Santos, G. L. Piccoli, F. H. R. França, and A. P. Petry, Analysis of mixed convection in transient laminar and turbulent flows in driven cavities, Int. J. Heat Mass Transf. 54 (21-22) (2011) 4585-4595.

[17] E. D. Dos Santos, A. P. Petry, L. A. O. Rocha, and F. H. R. França, Numerical Study of Forced Convection Lid-Driven Cavity Flows Using Large Eddy Simulation (LES), Int. J. Energy Power Eng. 7 (2013) 1669-1680.

[18] M. A. Ismael, I. Pop, and A. J. Chamkha, Mixed convection in a lid-driven square cavity with partial slip, Int. J. Therm. Sci. 82 (2014) 47-61.

[19] A. K. Kareem, H. A. Mohammed, A. K. Hussein, and S. Gao, Numerical investigation of mixed convection heat transfer of nanofluids in a lid-driven trapezoidal cavity, Int. Commun. Heat Mass Transf. 77 (2016) 195-205.

[20] A. J. Chamkha, S. H. Hussain, and Q. R. Abd-Amer, Mixed convection heat transfer of air inside a square vented cavity with a heated horizontal square cylinder, Numer. Heat Tr. A- Appl. 59 (1) (2011) pp. 58-79.

[21] H. F. Oztop, Z. Zhao, and B. Yu, Fluid flow due to combined convection in lid-driven enclosure having a circular body, Int. J. Heat Fluid Flow 30 (5) (2009) 886-901.

[22] N. S. Gibanov, M. A. Sheremet, H. F. Oztop, and K. Al-Salem, Convective heat transfer in a lid-driven cavity with a heat-conducting solid backward step under the effect of buoyancy force, Int. J. Heat Mass Transf. 112 (2017) 158-168. 
[23] X. Shi, and J. M. Khodadadi, Periodic state of fluid flow and heat transfer in a lid-driven cavity due to an oscillating thin fin, Int. J. Heat Mass Transf. 48 (25-26) (2005) 5323-5337.

[24] C. Sun, B. Yu, H. F. Oztop, Y. Wang, and J. Wei, Control of Mixed Convection in Lid-Driven Enclosures Using Conductive Triangular Fins, Int. J. Heat Mass Transf. 54 (2011) 894-909.

[25] M. Hatami, J. Zhou, J. Geng, D. Song, and D. Jing, Optimization of a lid-driven T-shaped porous cavity to improve the nanofluids mixed convection heat transfer, J. Mol. Liq. 231 (2017) 620-631.

[26] A. Bejan, Constructal-theory network of conducting paths for cooling a heat generating volume, Int. J. Heat Mass Transf. 40 (1997) 799-816.

[27] A. Bejan, 2000, Shape and Structure, from Engineering to Nature, Cambridge, United Kingdom: Cambridge University Press.

[28] A. Bejan, and M. Almogbel, Constructal T-shaped fins, Int. J. Heat Mass Transf. 43 (2000) 2101-2115.

[29] G. Lorenzini, C. Biserni, R.L. Correa, E.D. dos Santos, L.A. Isoldi and L.A.O. Rocha, Constructal design of T-shaped assemblies of fins cooling a cylindrical solid body, Int. J. Therm. Sci. 83 (2014) 96-103.

[30] E. da S.D. Estrada, T.M. Fagundes, L.A. Isoldi, E.D. dos Santos, G. Xie, and L.A.O. Rocha, Constructal Design Associated to Genetic Algorithm of Asymmetric V-Shaped Pathways, ASME-J. Heat Transf. 137 (2015) 061010.

[31] G. Xie, Y. Song, M. Asadi, and G. Lorenzini, Optimization of Pin-Fins for a Heat Exchanger by Entropy Generation Minimization and Constructal Law, ASME-J. Heat Transf. 137 (2015) 061901.

[32] D. Helbig, C. C. C. da Silva, M. de V. Real, E. D. dos Santos, L. A. Isoldi, and L.A.O. Rocha, Study About Buckling Phenomenon in Perforated Thin Steel Plates Employing Computational Modeling and Constructal Design Method, Lat. Am. J. Solids Struct. 13 (2016) 1912-1936.

[33] M. K. Rodrigues, R. da S. Brum, J. Vaz, L. A. O. Rocha, E. D. dos Santos, and L. A. Isoldi, Numerical investigation about the improvement of the thermal potential of an Earth-Air Heat Exchanger (EAHE) employing the Constructal Design method, Renew. Energ. 80 (2015) 538-551. 
[34] R. S. Vieira, A. P. Petry, L. A. O. Rocha, L. A. Isoldi, E. D. dos Santos, Numerical evaluation of a solar chimney geometry for different ground temperatures by means of Constructal design, Renew. Energ. 109 (2017) 222-234.

[35] G. M. Barros, G. Lorenzini, L. A. Isoldi, L. A. O. Rocha, and E. D. Dos Santos, Influence of mixed convection laminar flows on the geometrical evaluation of a triangular arrangement of circular cylinders, Int. J. Heat Mass Transf. 114 (2017) 1188-1200.

[36] J. C. Martins, M. M. Goulart, M. das N. Gomes, J. A. Souza, L. A. O. Rocha, L. A. Isoldi, E. D. dos Santos, Geometric evaluation of the main operational principle of an overtopping wave energy converter by means of Constructal Design, Renew. Energ. 118 (2018) 727-741.

[37] E. D. Dos Santos, L. A. Isoldi, M. N. Gomes, L. A. O. Rocha, 2017, The Constructal Design Applied to Renewable Energy Systems, In: Eduardo Rincón-Mejía; Alejandro de las Heras. (Org.) Sustainable Energy Technologies, $1^{\text {st }}$. ed., Boca Raton: CRC Press - Taylor \& Francis Group, v. 1, pp. 63-87.

[38] E. D. Dos Santos, L. A. Isoldi, J. A. Souza, M. M. Goulart, M. K. Rodrigues, F. M. Seibt, R. V. de Souza and L. A. O. Rocha, 2013, Constructal Design of a Rectangular Fin Intruded into Forced Convective Lid-Driven Cavity Flows, In: Proc. Constr. Law Conf.: v. 1, pp. 126-134.

[39] G. Lorenzini, B. S. Machado, L. A. Isoldi, E. D. Dos Santos and L. A. O. Rocha, Constructal Design of rectangular fin intruded into mixed convective lid-driven cavity flows, ASME-J. Heat Transf. 138 (10) (2016) 102501.

[40] E. S. Aldrighi, P. M. Rodrigues, B. D. A. Rodriguez, L. A. Isoldi, L. A. O. Rocha, and E. D. Dos Santos, Constructal Design of Rectangular Fin Intruded into Different Surfaces of Forced Convective Lid-Driven Cavity Flow, Int. J. Fluid Mech. Res. 43 (5-6) (2016) 418-440.

[41] A. L. Razera, T. M. Fagundes, F. M. Seibt, R. J. C. da Fonseca, D. J. Varela, P. R. B. Ortiz, F. R. Coelho, L. Z. Lessa, A. Schmidt, G. M. Furtado, E. D. dos Santos, L. A. Isoldi, and L. A. O. Rocha, Constructal Design of a Triangular Fin Inserted in a Cavity with Mixed Convection LidDriven Flow, Defect Diffus. Forum 372 (2016) 188-201.

[42] H. K. Versteeg, and W. Malalasekera, 2007, An introduction to computational fluid dynamics: the finite volume method, Pearson Education.

[43] FLUENT, version 14.0, User's guide, Ansys Inc., 2011.

[44] A. Bejan, 2013, Convection heat transfer, New York, EUA: John Wiley \& Sons. 
[45] A. Bejan and S. Lorente, Constructal theory of generation of configuration in nature and engineering, J. Appl. Phys. 100 (2006) 041-301.

[46] A. Bejan, and S. Lorente, 2008, Design with Constructal Theory, New York, EUA: John Wiley \& Sons.

[47] D. Gray, and A. Giorgini, The Validity of the Boussinesq Approximation for Liquids and Gases, Int. J. Heat Mass Transf. 19 (5) (1976) 545-551.

[48] S. Patankar, 1980, Numerical Heat Transfer and Fluid Flow, CRC press. 
FIGURES 


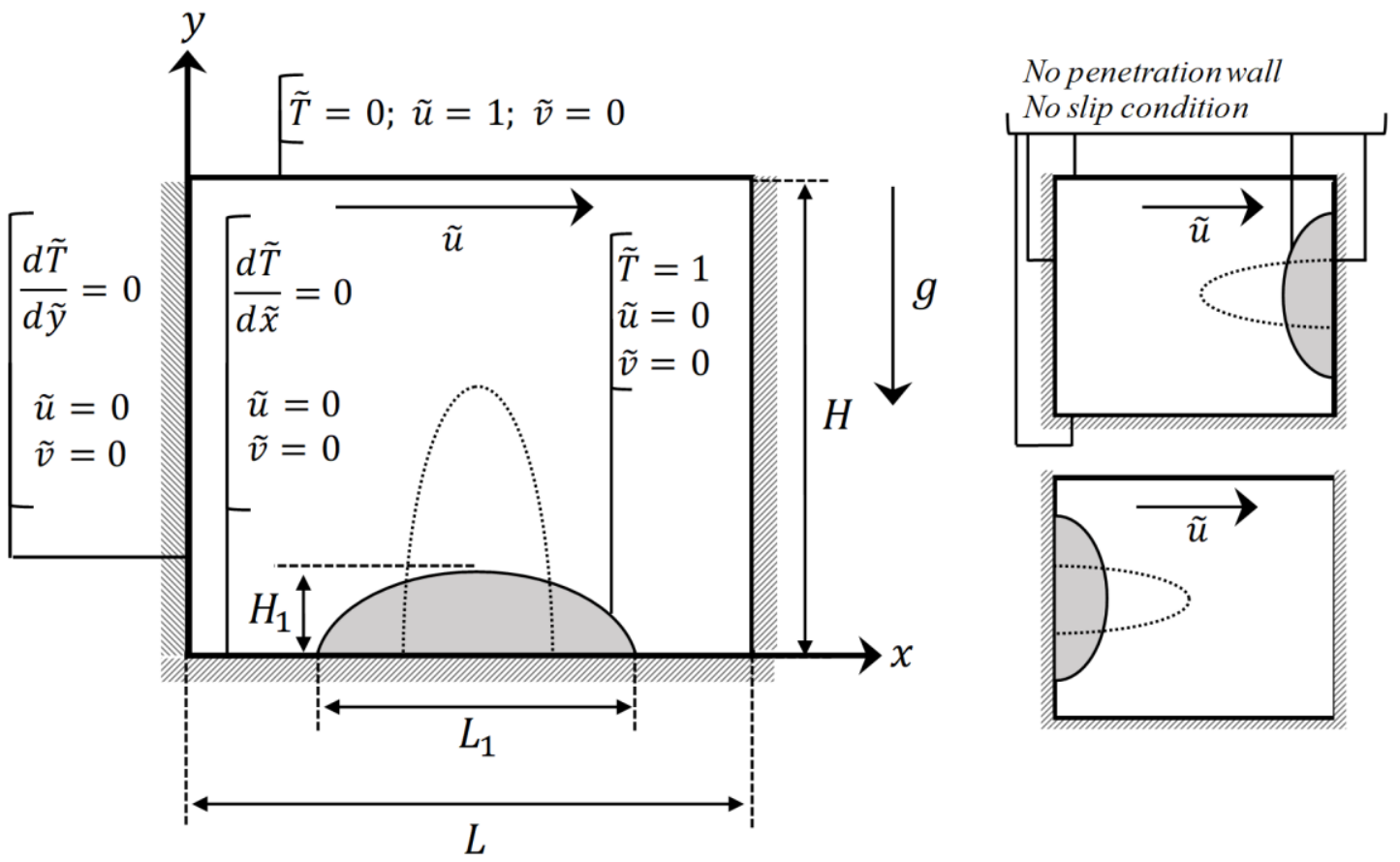

Figure 1 - Schematic representation of the domain consisting of the cavity and fin. 


\section{Constructal Design Method}

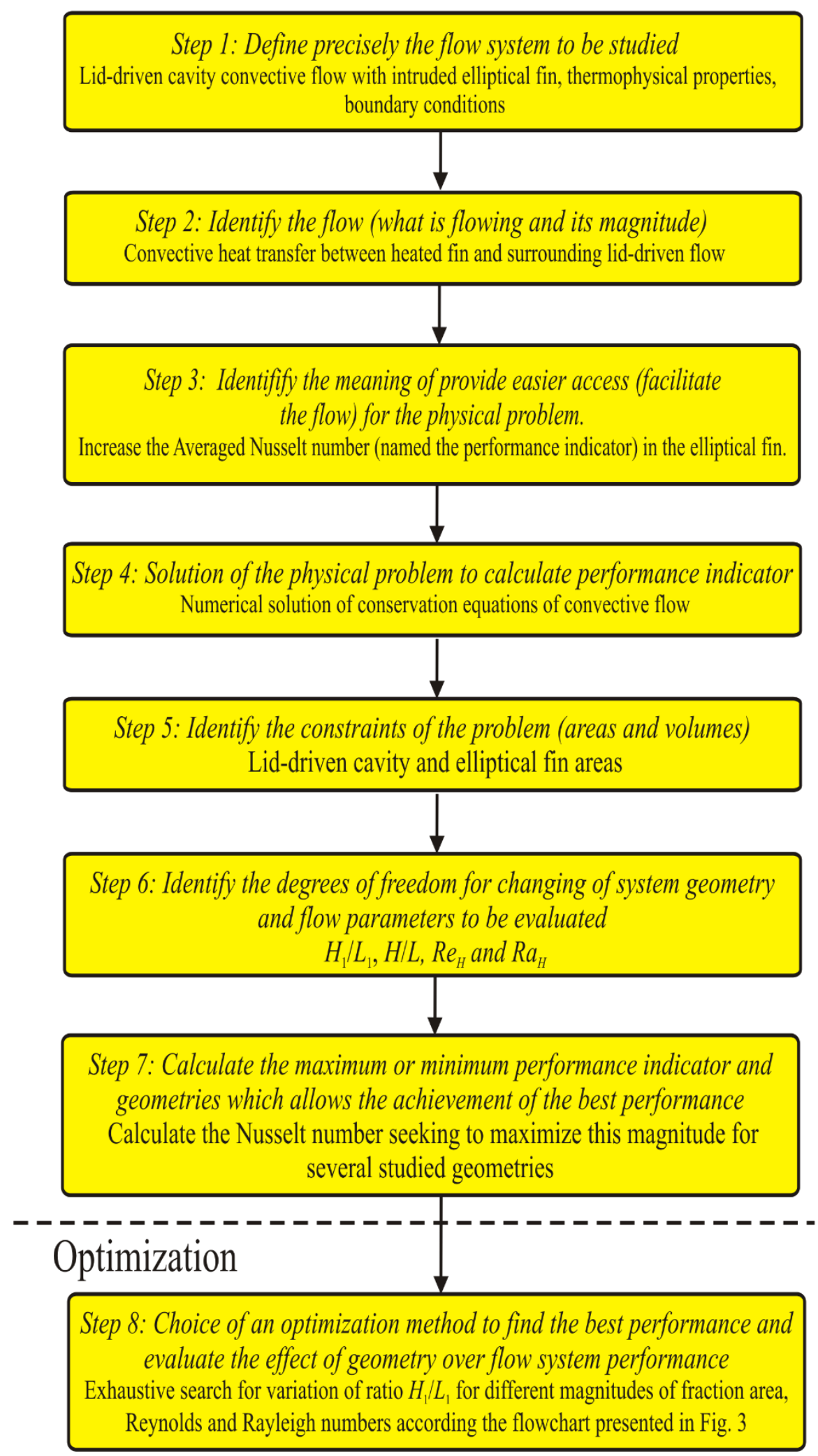

Figure 2 - Flowchart with application of Constructal Design and Exhaustive Search methods for the present problem. 


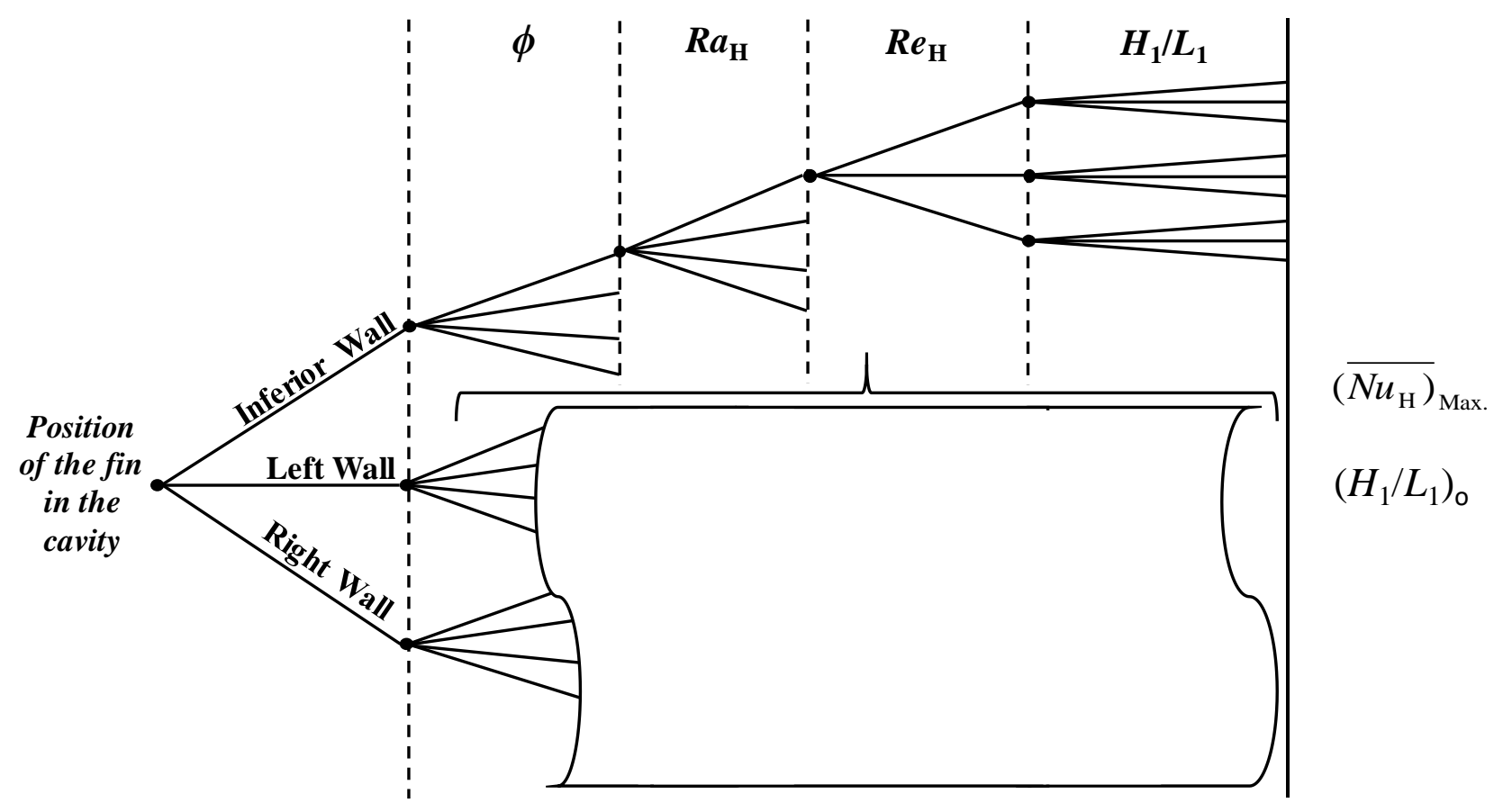

Figure 3 - Flowchart of performed optimization with exhaustive search. 


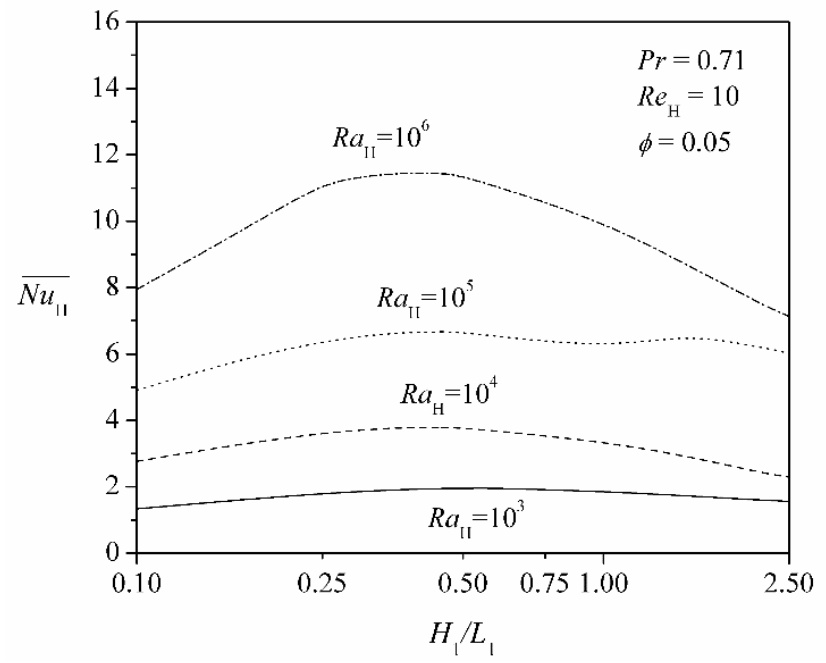

(a)

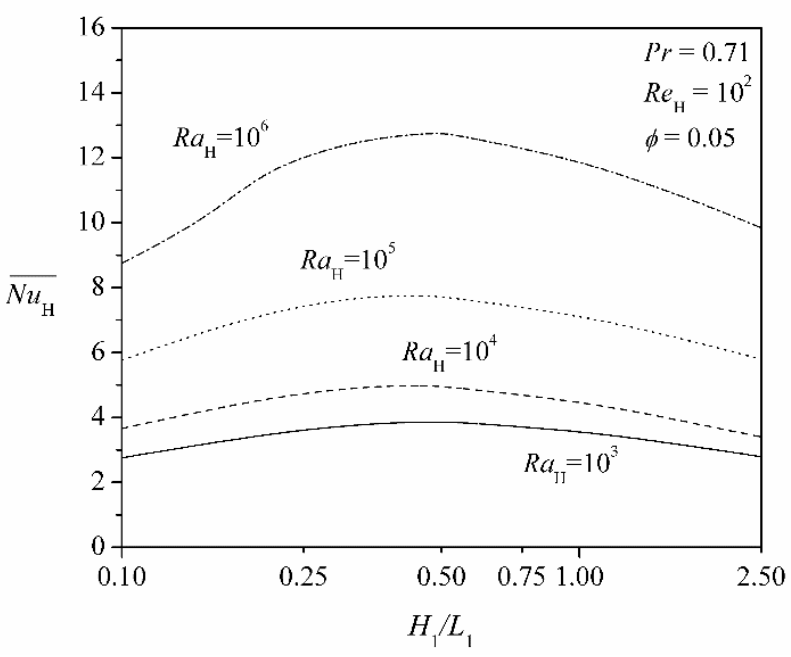

(b)

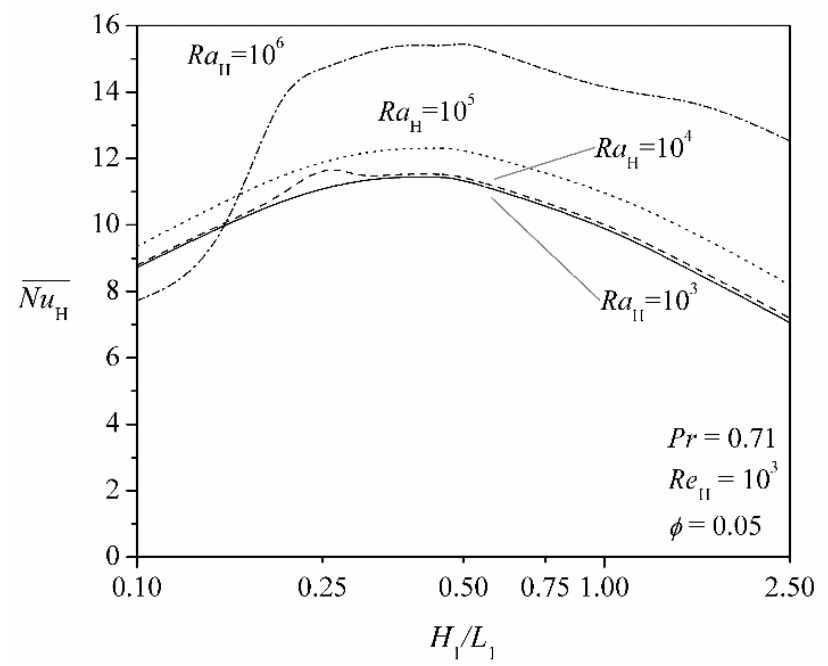

(c)

Figure 4 - Effect of the aspect ratio $H_{1} / L_{1}$ on the average Nusselt number $\overline{N u_{\mathrm{H}}}$ for different Rayleigh numbers: (a) $R e_{\mathrm{H}}=10$; (b) $R e_{\mathrm{H}}=10^{2}$; (c) $R e_{\mathrm{H}}=10^{3}$. 


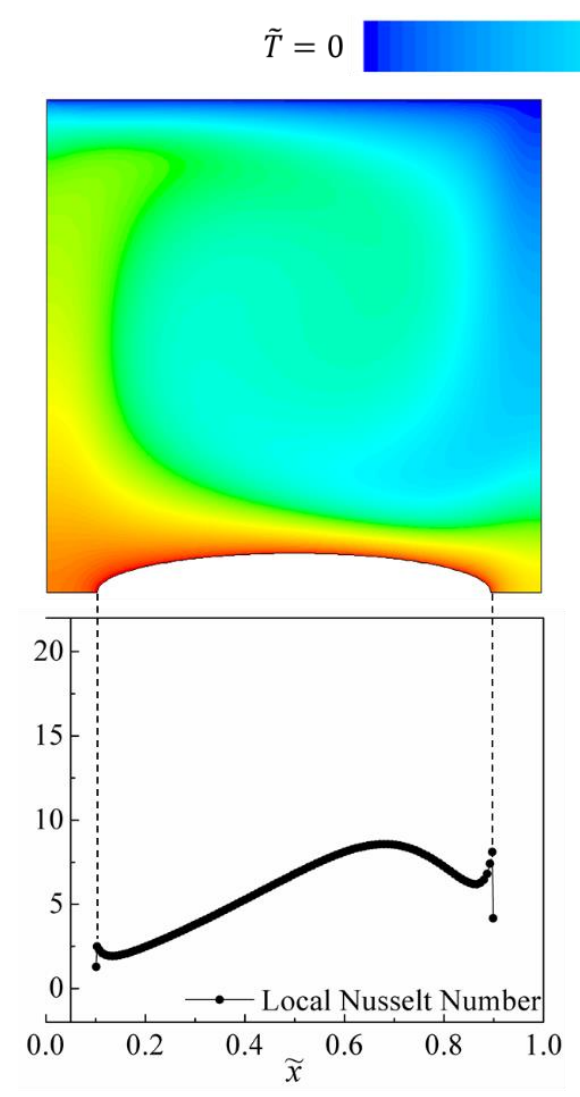

(a)

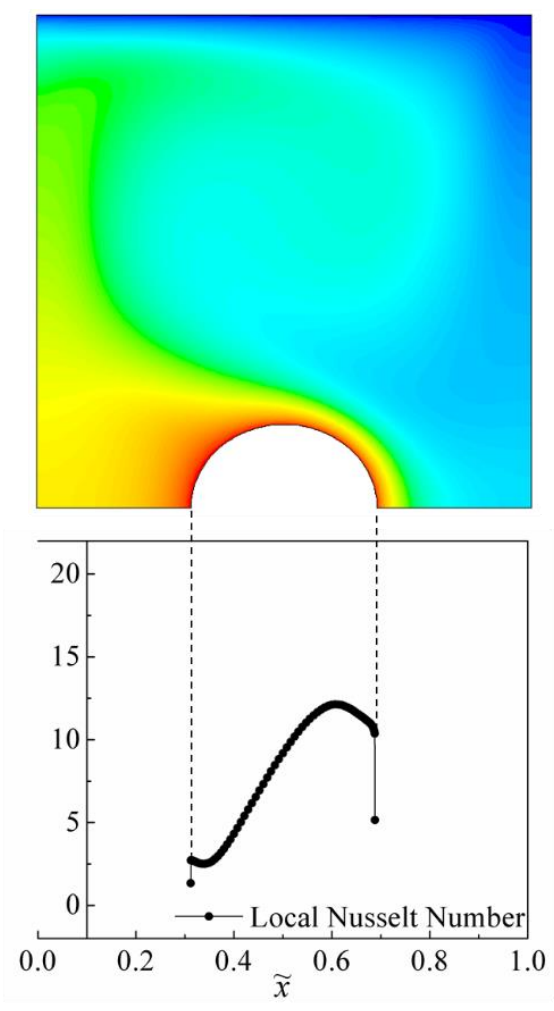

(b)

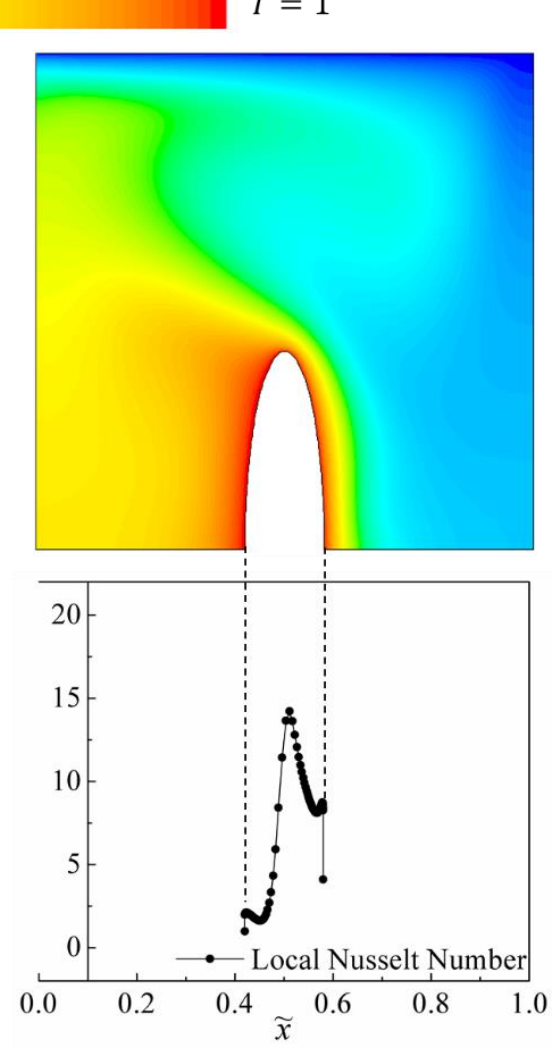

(c)

Figure 5 - Temperature fields and local Nusselt number for the extreme cases of $H_{1} / L_{1}$ studied and $\left(H_{1} / L_{1}\right)_{\mathrm{o}}$, for $R a_{\mathrm{H}}=10^{5}, R e_{\mathrm{H}}=10^{2}, \phi=0.05$ and $\operatorname{Pr}=0.71$ : (a) $H_{1} / L_{1}=0.10$; (b) $\left(H_{1} / L_{1}\right)_{\mathrm{o}}=0.45$; (c) $H_{1} / L_{1}=2.50$. 


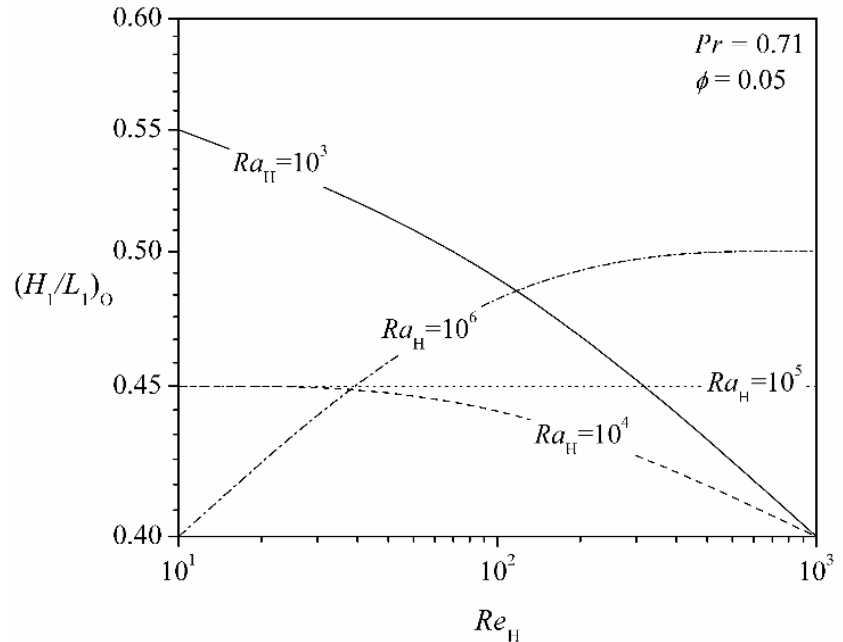

(a)

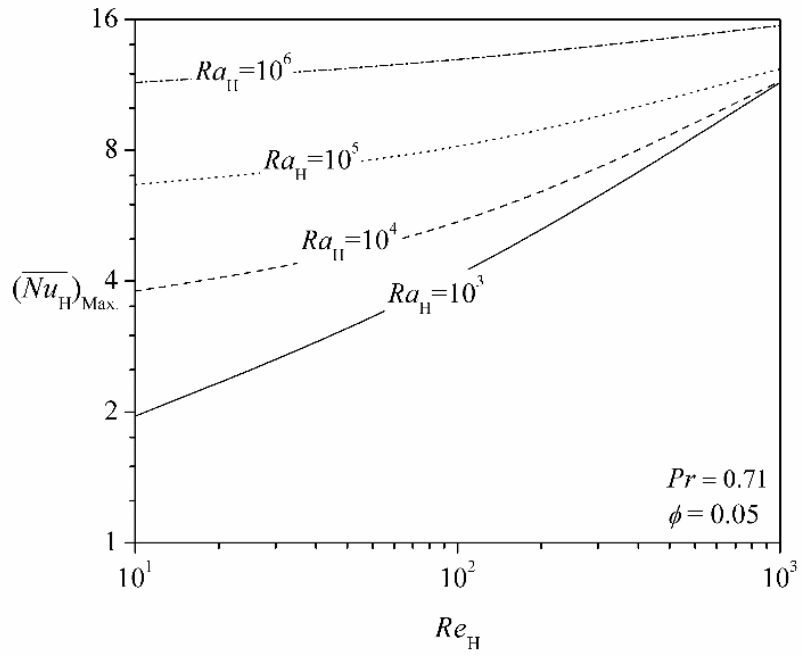

(b)

Figure 6 - Effect of the Reynolds number $\left(R_{\mathrm{H}}\right)$ for $\phi=0.05$ and $\operatorname{Pr}=0.71$ : (a) Optimal geometries $\left(H_{1} / L_{1}\right)_{\text {o. }}$; b) Maximum Nusselt number $\left(\overline{N u_{\mathrm{H}}}\right)_{\text {Max. }}$ 

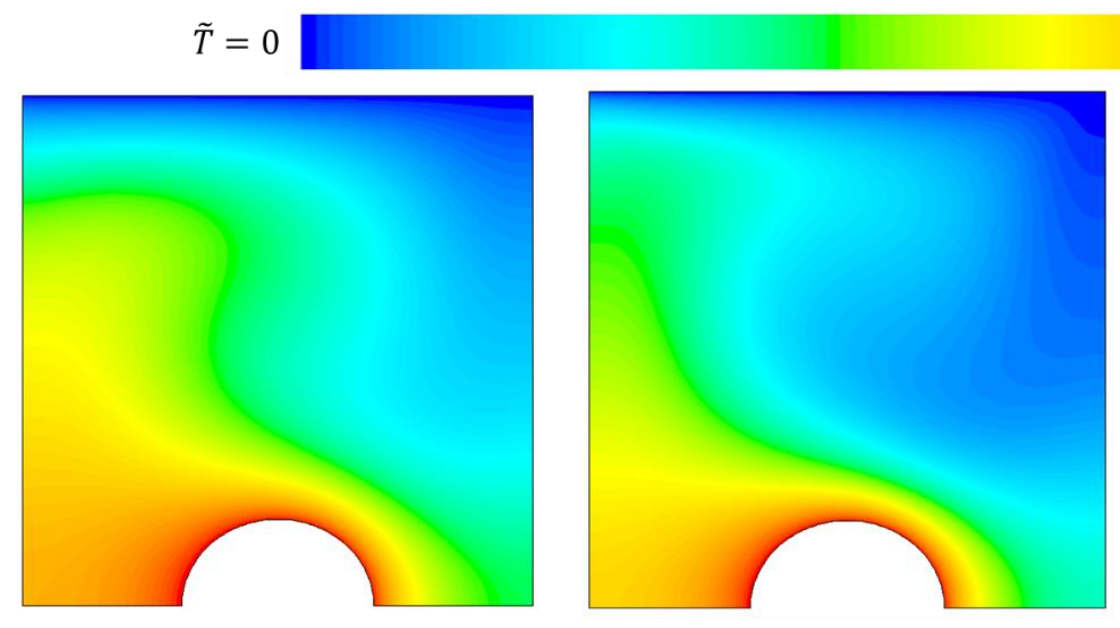

$$
\begin{gathered}
R e_{\mathrm{H}}=10 \\
R a_{\mathrm{H}}=10^{4} \\
\phi=0.05 \\
\left(H_{1} / L_{1}\right)_{\mathrm{o}}=0.45 \\
\left(N u_{H}\right)_{\text {Max. }}=3.7919
\end{gathered}
$$

$$
\begin{gathered}
R e_{\mathrm{H}}=10^{2} \\
R a_{\mathrm{H}}=10^{4} \\
\phi=0.05 \\
\left(H_{1} / L_{1}\right)_{\mathrm{o}}=0.45 \\
\left(N u_{H}\right)_{\text {Max. }}=4.9806
\end{gathered}
$$$$
\tilde{T}=1
$$

(a)

(b)

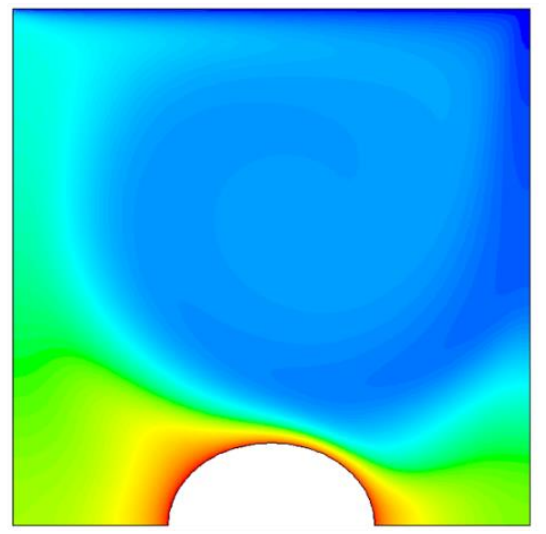

$$
\begin{aligned}
& R e_{\mathrm{H}}=10^{3} \\
& R a_{\mathrm{H}}=10^{4}
\end{aligned}
$$$$
\phi=0.05
$$

$$
\begin{gathered}
\left(H_{1} / L_{1}\right)_{\mathrm{o}}=0.40 \\
\left(N u_{H}\right)_{\text {Max. }}=11.5352
\end{gathered}
$$

(c)

Figure 7 - Temperature fields of the optimal geometries $\left(H_{1} / L_{1}\right)_{\mathrm{o}}$ for $R a_{\mathrm{H}}=10^{4}, \phi=0.05$ and $\operatorname{Pr}=$ 0.71: (a) $R e_{\mathrm{H}}=10$; (b) $R e_{\mathrm{H}}=10^{2}$; (c) $R e_{\mathrm{H}}=10^{3}$. 


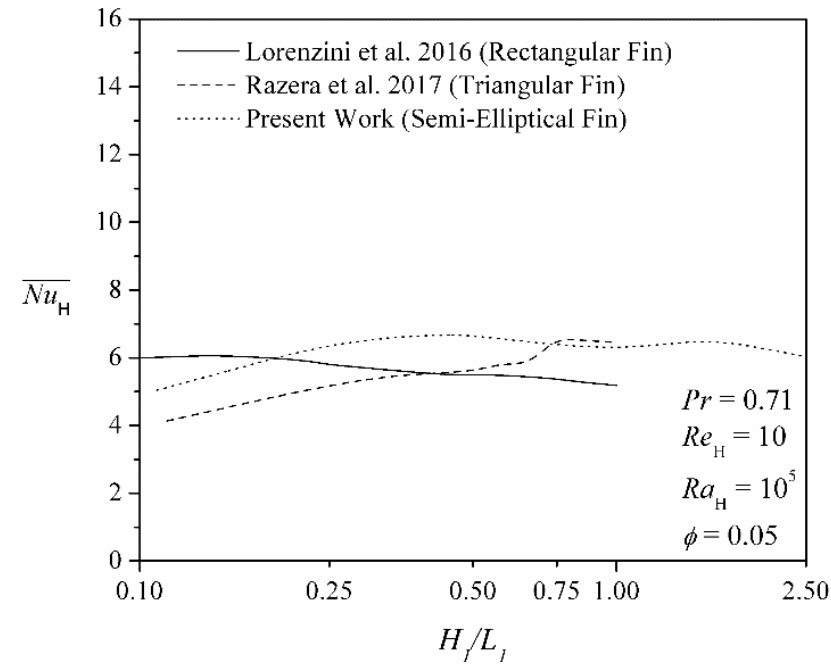

(a)

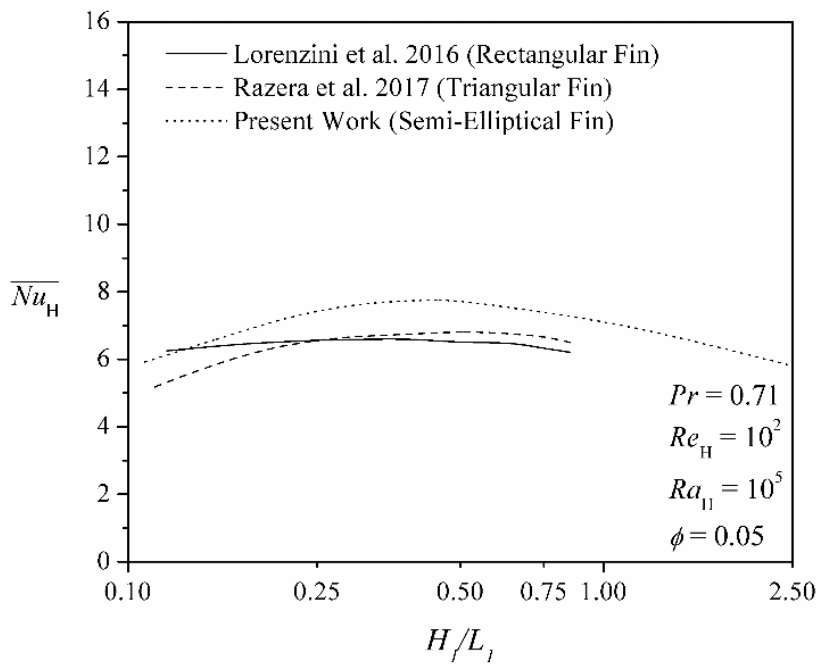

(b)

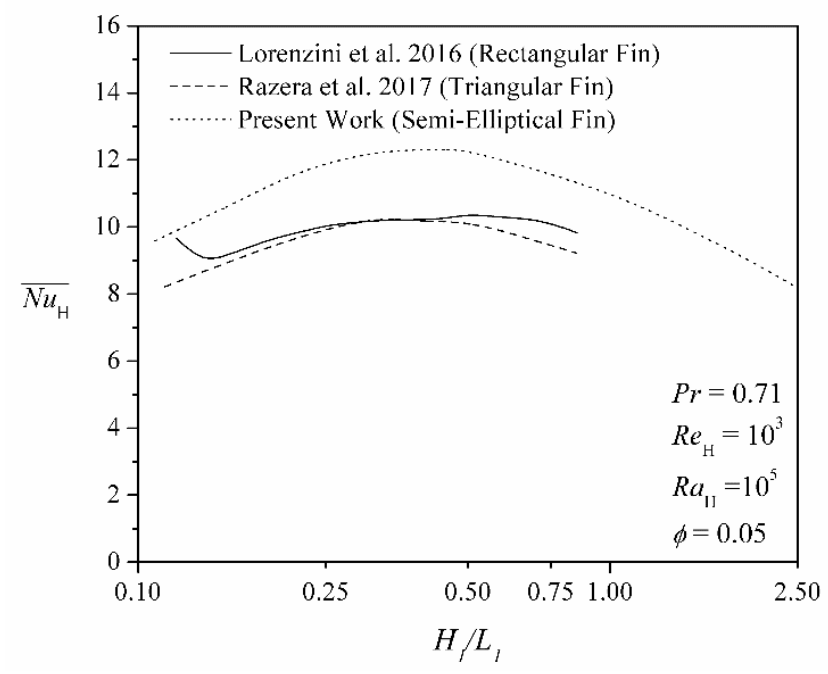

(c)

Figure 8 - Comparison of the effect of the aspect ratio $H_{1} / L_{1}$ on the average Nusselt number $\left(\overline{N u_{\mathrm{H}}}\right)$ in cavities with elliptical, rectangular and triangular fins, for $\operatorname{Ra} a_{\mathrm{H}}=10^{5}, \operatorname{Pr}=0.71$ and: (a) $\operatorname{Re} e_{\mathrm{H}}=10$; (b) $R e_{\mathrm{H}}=10^{2}$; (c) $R e_{\mathrm{H}}=10^{3}$. 


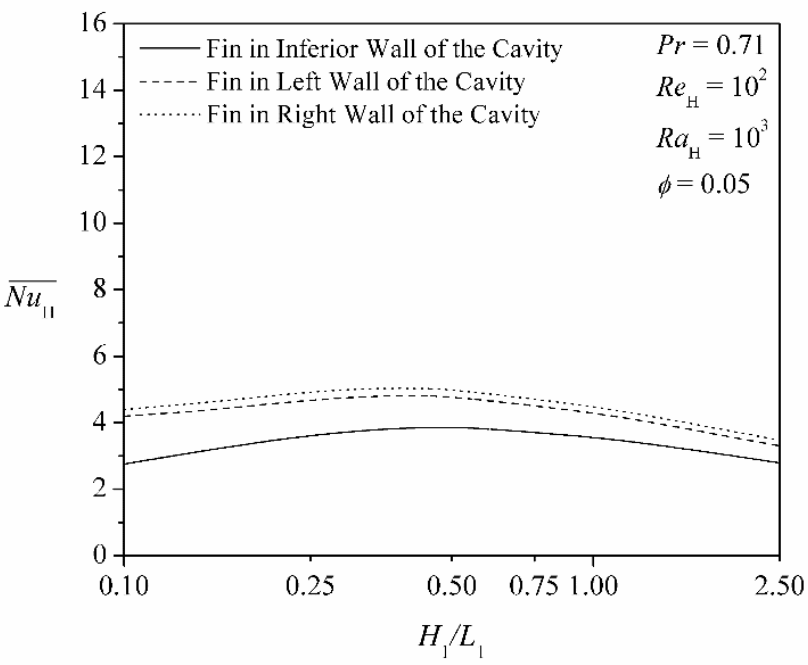

(a)

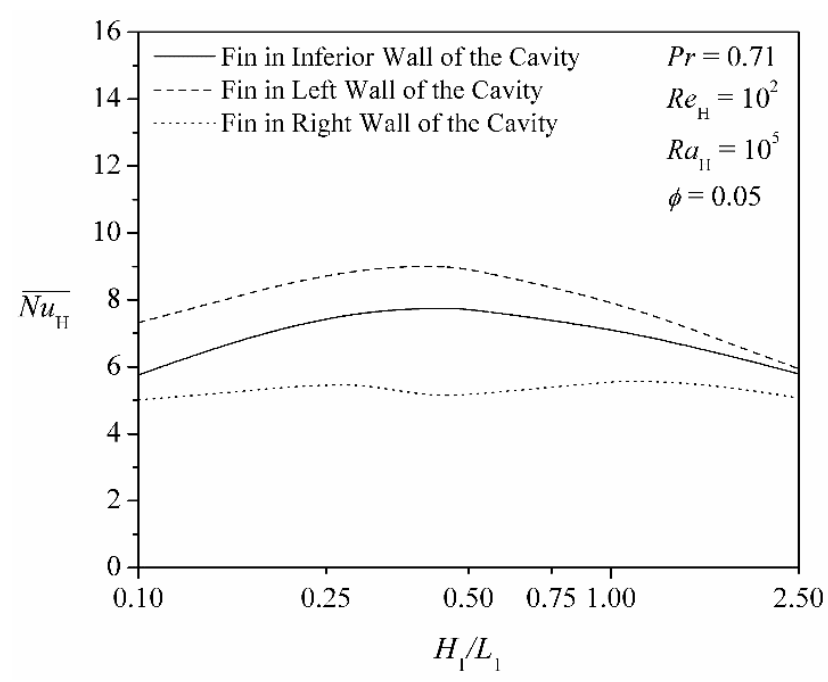

(c)

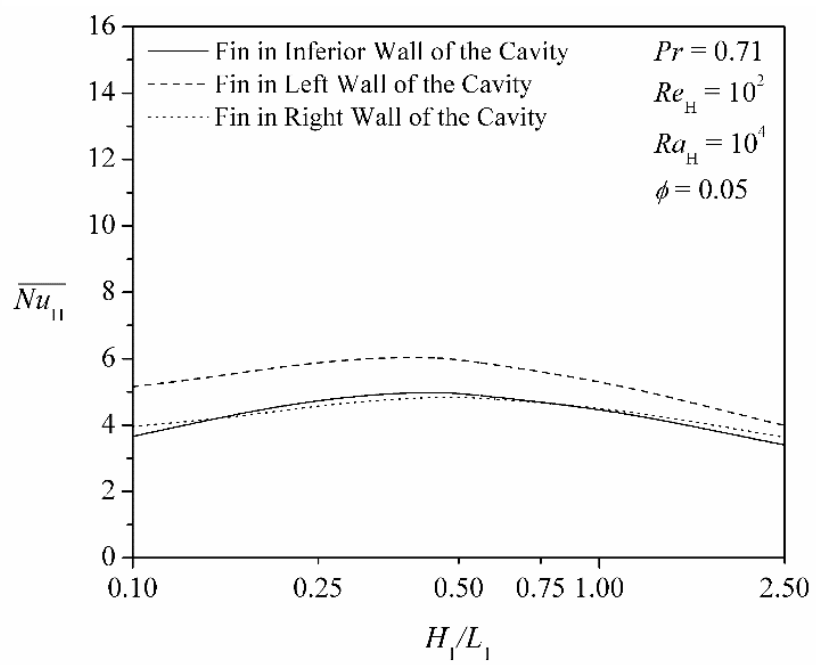

(b)

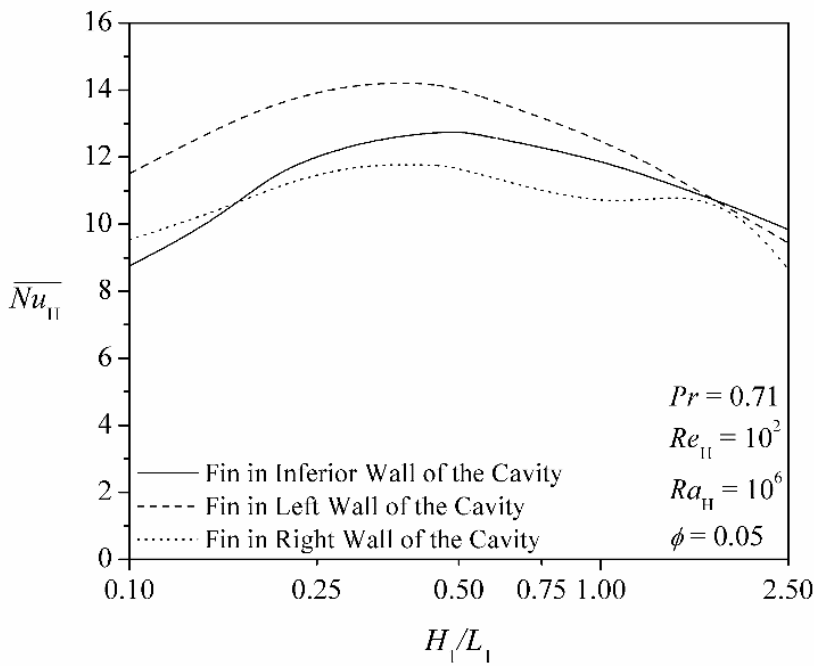

(d)

Figure 9 - Comparison of the effect of the aspect ratio $H_{1} / L_{1}$ on the average Nusselt number $\left(\overline{N u_{\mathrm{H}}}\right)$ in cavities with semi-elliptical fin inserted in inferior, left and right wall of the cavity, for $R e_{\mathrm{H}}=10^{2}$, $\operatorname{Pr}=0.71$ : (a) $R a_{\mathrm{H}}=10^{3}$; (b) $R a_{\mathrm{H}}=10^{4}$; (c) $R a_{\mathrm{H}}=10^{5}$; (d) $R a_{\mathrm{H}}=10^{6}$. 


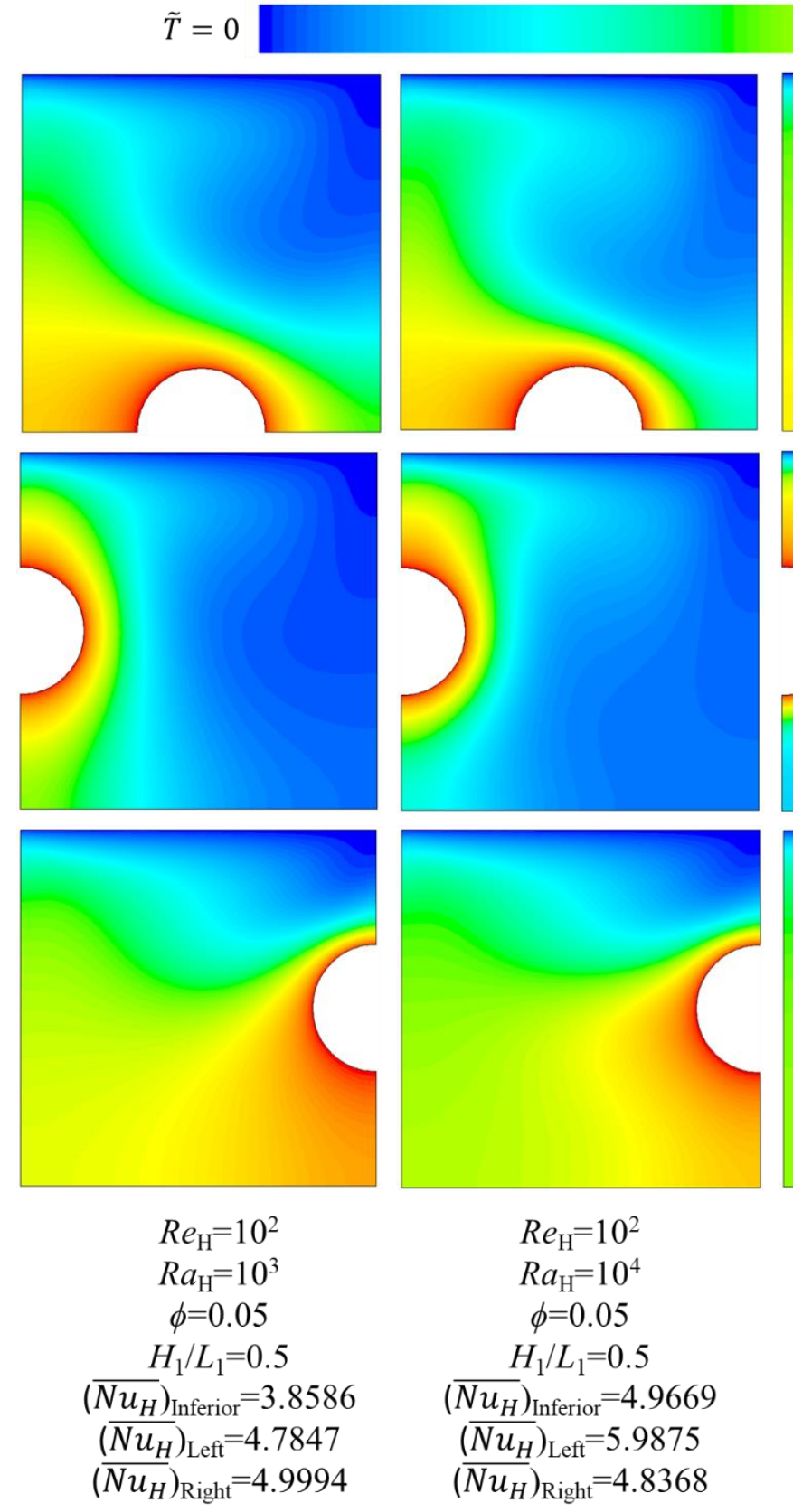

(a) (b)
$\tilde{T}=1$
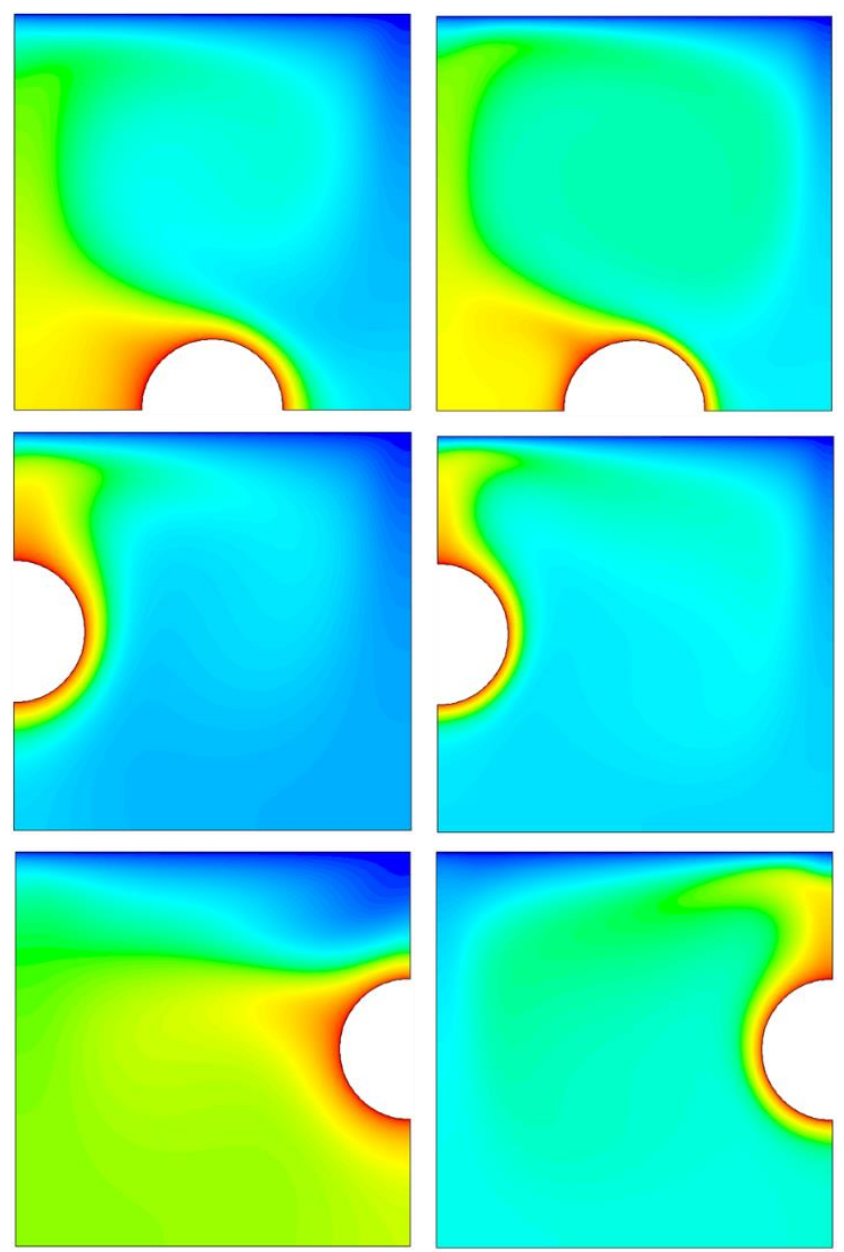

$$
\begin{gathered}
R e_{\mathrm{H}}=10^{2} \\
R a_{\mathrm{H}}=10^{5} \\
\phi=0.05 \\
H_{1} / L_{1}=0.5 \\
\left(\overline{N u_{H}}\right)_{\text {Inferior }}=7.7371 \\
\left(\overline{N u_{H}}\right)_{\text {Left }}=8.9423 \\
\left(\overline{N u_{H}}\right)_{\text {Right }}=5.1666
\end{gathered}
$$

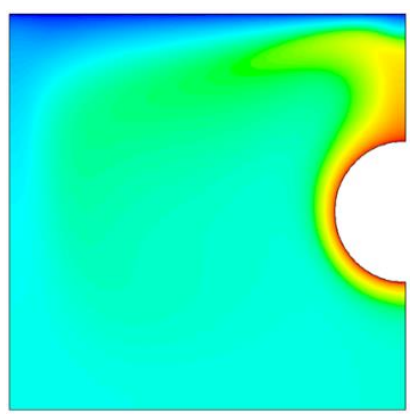

(c)

$$
\begin{gathered}
R e_{\mathrm{H}}=10^{2} \\
R a_{\mathrm{H}}=10^{6} \\
\phi=0.05 \\
H_{1} / L_{1}=0.5
\end{gathered}
$$$$
\left(\overline{N u_{H}}\right)_{\text {Inferior }}=12.7580
$$$$
\left(\overline{N u_{H}}\right)_{\text {Left }}=14.0517
$$$$
\left(\overline{N u_{H}}\right)_{\text {Right }}=11.6876
$$

(d)

Figure 10 - Temperature fields in cavities with semi-elliptical fin inserted in inferior, left and right wall of the cavity, for $R e_{\mathrm{H}}=10^{2}, \operatorname{Pr}=0.71, \phi=0.05$ and $H_{1} / L_{1}=0.50$ : (a) $R a_{\mathrm{H}}=10^{3}$; (b) $R a_{\mathrm{H}}=10^{4}$;
(c) $R a_{\mathrm{H}}=10^{5}$;
(d) $R a_{\mathrm{H}}=10^{6}$. 


$$
\tilde{T}=0
$$

$\tilde{T}=1$

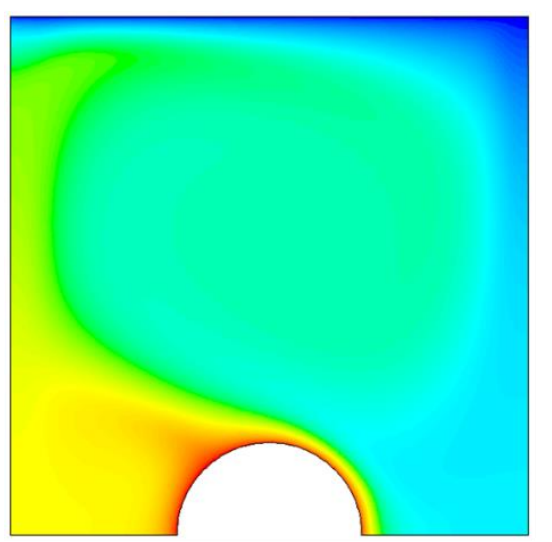

$R e_{\mathrm{H}}=10^{2}$

$R a_{\mathrm{H}}=10^{6}$

$\phi=0.05$

$\left(H_{1} / L_{1}\right)_{\mathrm{o}}=0.5$
$\left(\overline{N u_{H}}\right)_{\text {Max. }}=12.7580$

(a)

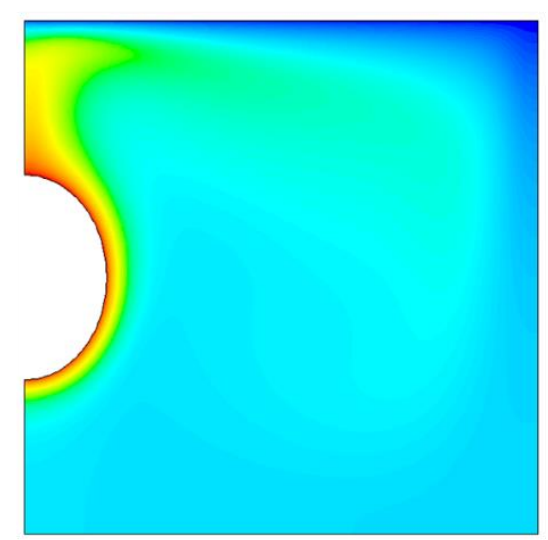

$R e_{\mathrm{H}}=10^{2}$

$R a_{\mathrm{H}}=10^{6}$

$\phi=0.05$

$\left(H_{1} / L_{1}\right)_{\mathrm{o}}=0.40$
$\left(\overline{N u_{H}}\right)_{\text {Max. }}=14.2171$

(b)

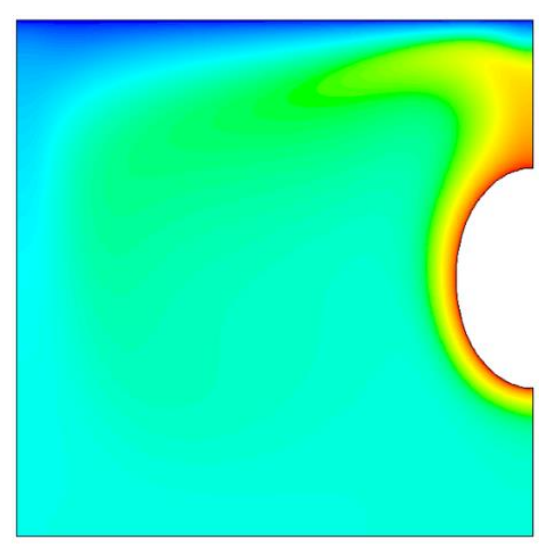

$R e_{\mathrm{H}}=10^{2}$

$R a_{\mathrm{H}}=10^{6}$

$\phi=0.05$

$\left(H_{1} / L_{1}\right)_{\mathrm{o}}=0.40$
$\left(\overline{N u_{H}}\right)_{\text {Max. }}=11.7738$

(c)

Figure 11 - Temperature fields of the optimal geometries $\left(\left(H_{1} / L_{1}\right)_{\mathrm{o}}\right)$ for $R a_{\mathrm{H}}=10^{2}, R e_{\mathrm{H}}=10^{2}, \phi=$ 0.05 and $\operatorname{Pr}=0.71$ : (a) Fin in the inferior wall of the cavity; (b) Fin in the left wall of the cavity; (c) Fin in the right wall of the cavity. 


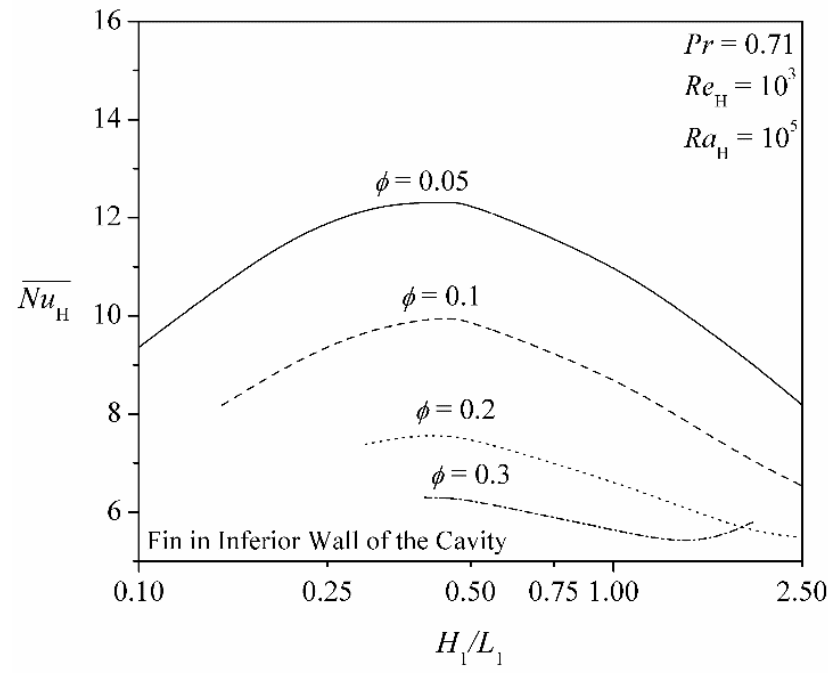

(a)

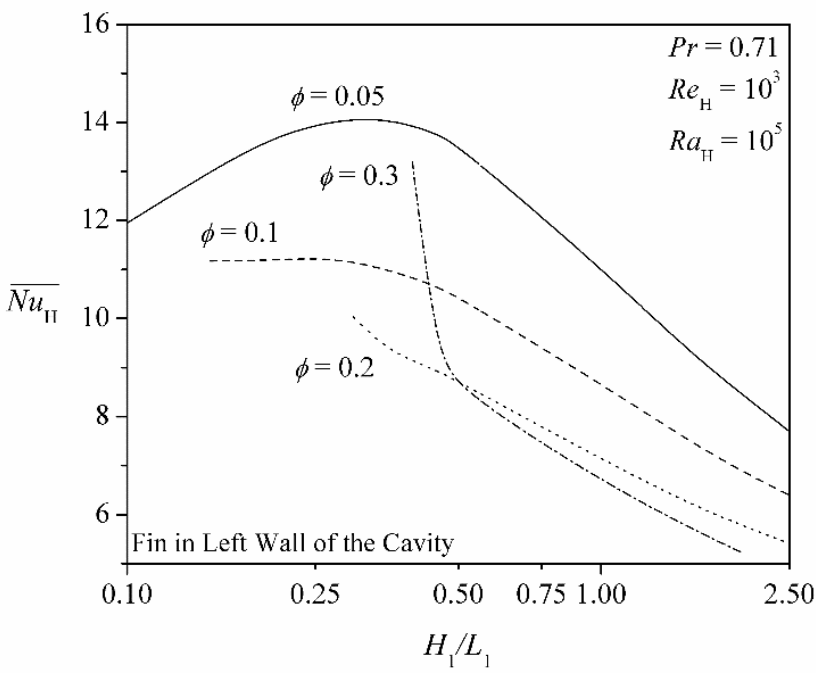

(b)

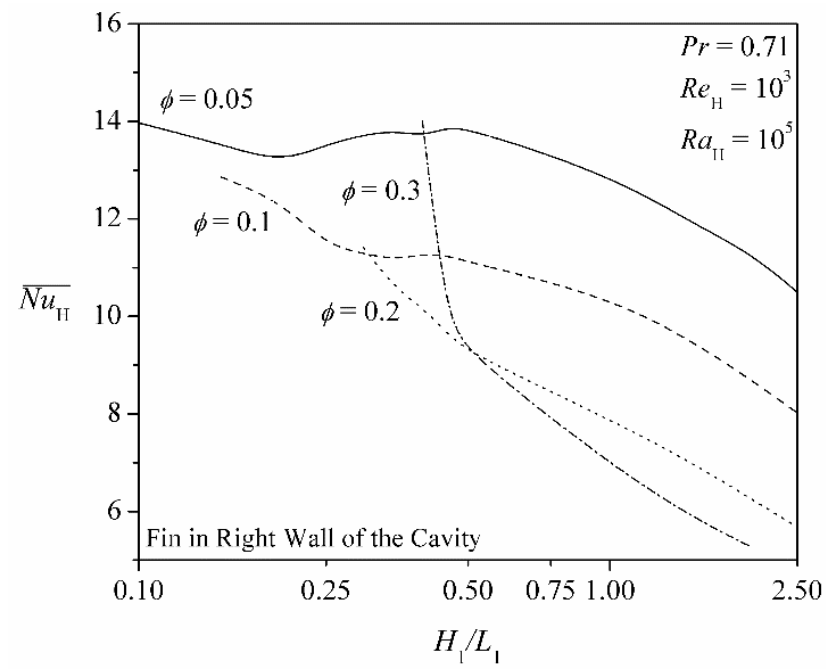

(c)

Figure 12 - Comparison of the effect of the aspect ratio $H_{1} / L_{1}$ on the average Nusselt number $\left(\overline{N u_{\mathrm{H}}}\right)$ for different fractions of area of the fin $(\phi)$, for $\operatorname{Re} e_{\mathrm{H}}=10^{3}, \operatorname{Ra} a_{\mathrm{H}}=10^{5}$ and $\operatorname{Pr}=0.71$ : (a) Fin in the inferior wall of the cavity; (b) Fin in the left wall of the cavity; (c) Fin in the right wall of the cavity. 


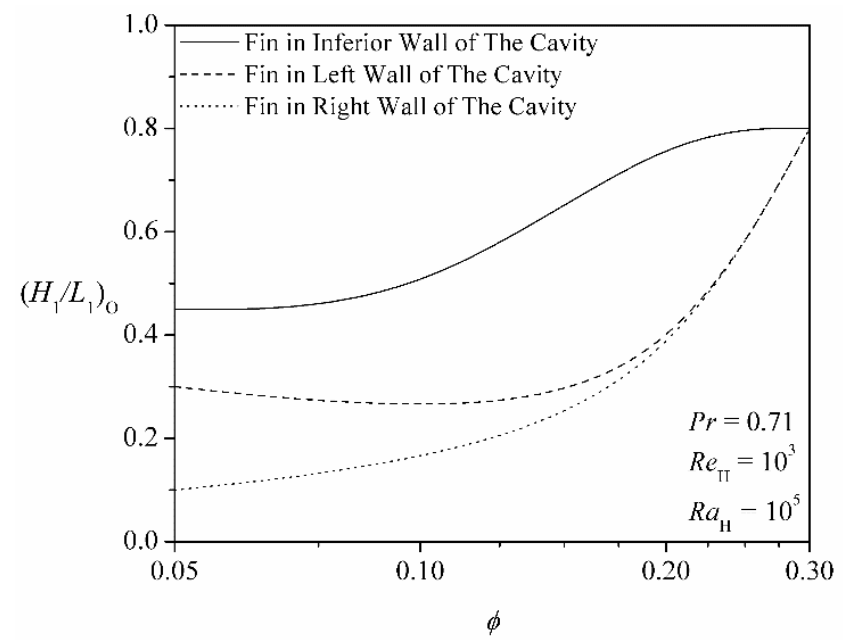

(a)

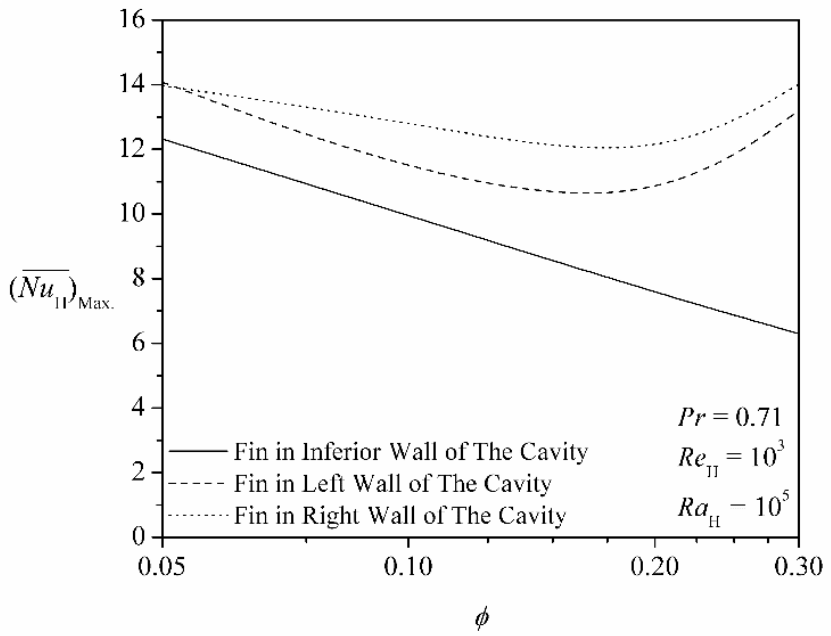

(b)

Figure 13 - Effect of the fraction of area of the fin $(\phi)$, for $\operatorname{Re} e_{\mathrm{H}}=10^{3}, \operatorname{Ra} a_{\mathrm{H}}=10^{5}$ and $\operatorname{Pr}=0.71$ : (a) Optimal geometries $\left(H_{1} / L_{1}\right)_{\text {o.; }}$; (b) Maximum Nusselt number $\left(\overline{N u_{\mathrm{H}}}\right)_{\text {Max. }}$ 